\title{
Characterization of an AA9 LPMO from Thielavia australiensis, TausLPMO9B, under industrially relevant lignocellulose saccharification conditions
}

\author{
F. Calderaro ${ }^{1,2^{*}} \mathbb{0}$, M. Keser $^{1}$, M. Akeroyd ${ }^{1}$, L. E. Bevers ${ }^{1}$, V. G. H. Eijsink ${ }^{3}$, A. Várnai ${ }^{3}$ and M. A. van den Berg ${ }^{1}$
}

\begin{abstract}
Background: The discovery of lytic polysaccharide monooxygenases (LPMO) has changed our perspective on enzymatic degradation of plant biomass. Through an oxidative mechanism, these enzymes are able to cleave and depolymerize various polysaccharides, acting not only on crystalline substrates such as chitin and cellulose, but also on other polysaccharides, such as xyloglucan, glucomannan and starch. Despite their widespread use, uncertainties related to substrate specificity and stereospecificity, the nature of the co-substrate, in-process stability, and the nature of the optimal reductant challenge their exploitation in biomass processing applications.

Results: In this work, we studied the properties of a novel fungal LPMO from the thermophilic fungus Thielavia australiensis, TausLPMO9B. Heterologous expression of TausLPMO9B in Aspergillus niger yielded a glycosylated protein with a methylated N-terminal histidine showing LPMO activity. High sequence identity of the AA9 domain to that of MtLPMO9B (MYCTH_80312) from Myceliophthora thermophila (84\%) indicated strictly C1-oxidizing activity on cellulose, which was confirmed experimentally by the analysis of products released from cellulose using HPAEC. The enzyme was stable and active at a pH ranging from 4 to 6 , thus matching the conditions commonly used in industrial biomass processing, where a low pH (between 4 and 5) is used due to the pH-optima of commercial cellulases and a desire to limit microbial contamination.

Conclusion: While the oxidative cleavage of phosphoric acid swollen cellulose (PASC) by TausLPMO9B was boosted by the addition of $\mathrm{H}_{2} \mathrm{O}_{2}$ as a co-substrate, this effect was not observed during the saccharification of acid pretreated corn stover. This illustrates key differences between the lab-scale tests with artificial, lignin-free substrates and industrial settings with lignocellulosic biomass as substrate.
\end{abstract}

Keywords: Lytic polysaccharide monooxygenase, Enzyme assay, Cellulose, Lignocellulosic biomass, Thielavia australiensis, Corn stover, $\mathrm{H}_{2} \mathrm{O}_{2}$

*Correspondence: Federica.Calderaro@dsm.com

1 DSM Biotechnology Center, PP 699-0310, Alexander Fleminglaan 1, 2613 AX Delft, The Netherlands

Full list of author information is available at the end of the article

\begin{abstract}
Background
Due to the increasing demand for renewable alternatives to fossil resources for the production of fuels and chemicals, the attention towards the utilization of lignocellulosic material to generate second-generation biofuels has grown exponentially in recent years $[1,2]$. Despite the abundance of lignocellulosic material, constituting the structural part of the plant cell wall, its utilization as an
\end{abstract}


industrial feedstock poses some challenges, largely due to its recalcitrant nature [3, 4]. Lignocellulose is mainly composed of cellulose, hemicellulose and lignin, closely interlinked together to form a strong matrix that, in nature, provides plants with resistance to mechanical and microbial attack [5]. Although the polysaccharides constituting (hemi)cellulose can be enzymatically converted into fermentable sugars to produce biofuels, the tightly packed structure of the plant cell wall hinders the accessibility of enzymes to the substrate. Therefore, chemical and/or physical pretreatments are necessary to allow opening of this structure [6]. Next, an efficient enzymatic cocktail to break down the plant cell wall structure and release monosaccharides, is key in making the production of second-generation biofuels a commercially viable process [7]. Hydrolysis of cellulose, in particular, relies on the synergistic action of a mixture of different enzymes. Cellobiohydrolases and endoglucanases cleave, respectively, at the end or in the internal part of the cellulose chains and release cellobiose and longer cello-oligosaccharides, which are finally hydrolyzed to glucose by $\beta$-glucosidases [4]. These enzymes are classified as glycoside hydrolases $(\mathrm{GH})$ in the CAZy (Carbohydrate Active Enzyme) database [8], based on sequence similarity.

Lytic polysaccharide monooxygenases (LPMOs) have been discovered to contribute to the deconstruction of recalcitrant polysaccharides by conventional GHs in these enzyme cocktails. With their oxidative nature, LPMOs have changed the classical view on cellulose depolymerization as a process solely depending on hydrolytic enzymes [9]. Due to their ability to boost the efficiency of cellulolytic enzymes in the saccharification of lignocellulosic biomass [10, 11], LPMOs form today a crucial component in industrial enzymatic preparations [12]. To optimize the saccharification step, it is necessary to assess the biochemical properties of the involved enzymes under relevant process conditions and select the most efficient enzymes and process conditions for a particular process. While the traditional GHs have already been known for decades and have been extensively studied, LPMOs are a class of enzymes whose features, including their kinetics and stability during lignocellulose hydrolysis, still need to be fully elucidated to optimize their utilization in an industrial setting $[13,14]$.

Fungal cellulose-active LPMOs were formerly classified as GH61 endoglucanase. After the discovery of their true nature [9], GH61s were reclassified as family 9 auxiliary activities (AAs) in the CAZy database. There are currently seven AA families in the CAZy database (AA9-AA11, AA13-AA16) that comprise LPMOs from different sources, including bacteria, plant, fungi and insects [15]. The LPMO reaction starts with the reduction of the active-site copper from $\mathrm{Cu}^{2+}$ to $\mathrm{Cu}^{+}$by an external electron donor, which can be a small molecule, such as ascorbic acid, or an enzyme, such as cellobiose dehydrogenase [16-18]. Of note, electron donors can drive LPMO reaction to varying extents [16, 19]; thus, the selection of electron donor will determine apparent enzyme efficiency. Several studies have shown that reduction of LPMOs acting on lignin-rich lignocellulosic material does not require addition of external electron donors [19-24], suggesting a key impact of lignin on LPMO catalytic performance. The reduction step is followed by a reaction with an oxygen co-substrate, originally proposed to be $\mathrm{O}_{2}$ [9], that will eventually result in the hydroxylation of either the $\mathrm{C} 1$ or $\mathrm{C} 4$ carbon in the glycosidic bond of the polysaccharide. The hydroxylated glycosidic bond is unstable and will break [25], leading to the formation of an aldonolactone (C1-oxidation) or a 4-ketoaldose (C4-oxidation) [26, 27]. In 2017, the $\mathrm{O}_{2}$-driven mechanism was challenged, by proposing $\mathrm{H}_{2} \mathrm{O}_{2}$ as the relevant co-substrate for LPMO [18]. Since then, there is growing evidence in the literature in support of the $\mathrm{H}_{2} \mathrm{O}_{2}$-driven mechanism [23, 28-31]. While in both cases, activation of the enzyme depends on enzyme reduction, the $\mathrm{O}_{2}$-driven reaction requires delivery of two electrons per catalytic cycle, whereas a reduced LPMO can catalyze multiple reactions with $\mathrm{H}_{2} \mathrm{O}_{2}$ without any further electron supply.

LPMOs are quite abundant in filamentous fungi [32], but the biological role of this abundance remains unclear. There are indications that LPMOs may have evolved to adapt to various plant cell wall substructures and electron donors [33]. Intriguingly, the number of LPMOs in (thermophilic) filamentous fungi and their expression levels vary to a great extent. As an example, Thielavia australiensis encodes 15 AA9 LPMOs in its genome (Genozyme (http://genome.fungalgenomics.ca/; [34]).

Industrial enzyme cocktails are generally produced in filamentous fungal systems $[35,36]$. On the other hand, many of the fungal LPMOs studied to date have been produced in Pichia pastoris, a preferred expression system for detailed enzyme characterization because of a low background of plant cell wall-active CAZymes. Notably, LPMOs expressed in P. pastoris carry different posttranslational modifications (PTMs), including the lack of methylation at the N-terminal His [37] and different glycosylation patterns, compared to those expressed in fungal hosts. While the individual effects of these PTMs on LPMO activity are little understood, Petrović et al. have shown recently that the (methylated) variant of TaLPMO9A produced in Aspergillus niger has higher functional stability than a (non-methylated) variant produced in P. pastoris [38]. Concerning glycosylations, some studies have suggested that $\mathrm{N}$-glycosylation near the catalytic site could be involved, in some cases, in substrate binding 
of LPMOs [39]. Glycosylation, in certain cases, may complement substrate binding by cellulose-specific Carbohydrate-Binding Modules (CBMs). Despite the role of these modifications still being uncertain, producing LPMOs in a filamentous fungal host ensures that the produced enzymes are representative for the ones that will be used in commercial applications.

For industrial biomass processing, conducting industrial enzymatic saccharification at higher temperature brings many advantages, such as reduced risk of microbial contaminations or reduced viscosity of the material. Thermophilic fungi, defined as fungi able to grow at temperatures of $50{ }^{\circ} \mathrm{C}$ or above $[40,41]$, represent an interesting source of potentially thermostable enzymes. So far, different LPMOs from thermophilic/thermotolerant fungi have been characterized, including enzymes from Myceliophthora thermophila [19], Thermoascus aurantiacus [38], Thielavia terrestris [10] and Malbranchea cinnamomea [42]. Another aspect in the discovery of novel LPMOs is their ability to perform well under conditions that are compatible with the commonly used acidic pretreatment ( $\mathrm{pH}$ between 2 and 3 ) of lignocellulosic material. Thus, LPMOs from acid-tolerant, thermophilic filamentous fungi are of interest. This study focused on the characterization of such an LPMO, TausLPMO9B, from $T$. australiensis, which is, together with $T$. terrestris, the only described thermophilic species of the genus Thielavia [41]. TausLPMO9B was identified as part of a fungal secretome analysis project. TausLPMO9B was expressed in A. niger, an industrially relevant production organism, and assessed in terms of substrate specificity, oxidative regiospecificity, temperature and $\mathrm{pH}$ dependency, electron donor specificity, co-substrate utilization $\left(\mathrm{H}_{2} \mathrm{O}_{2}\right.$ and $\left.\mathrm{O}_{2}\right)$ and performance during biomass degradation. As lignocellulosic feedstock is a complex material, it is rather challenging to use it as a substrate for biochemical characterization of an LPMO: in the presence of a cellulase mix, C1-oxidized products are converted to gluconic acid and cellobionic acid, which are difficult to discriminate from other products with a similar elution profiles. Therefore, we also included phosphoric acid swollen cellulose (PASC) as a cleaner, non-natural substrate to allow for more detailed biochemical studies, and we assessed activity on this model cellulose (PASC) as well as hemicelluloses (isolated hemicelluloses), in addition to pretreated corn stover.

\section{Results}

\section{Sequence analysis and homology model}

cDNA from $T$. australiensis encoding an AA9 LPMO (Table S1) was cloned in A. niger [34]. The enzyme was expressed and active, making this LPMO a suitable candidate for biochemical and functional characterization. The product encoded by the 984-basepair-long gene was named TausLPMO9B (due to its high sequence identity with MtLPMO9B from $M$. thermophila; Additional file 1: Table S2) and consists of a typical N-terminal AA9 domain, a linker region and a C-terminal CBM1 domain (Additional file 1: Table S1). Figure 1 shows a multiple sequence alignment of the catalytic domains of TausLPMO9B and selected LPMOs with experimentally confirmed oxidative regioselectivity (i.e. strict $\mathrm{C} 1$-, strict C4- or mixed C1/C4-oxidizing LPMOs) from $M$. thermophila (MtLPMO9B, UniProt ID G2QCJ3, strictly C1-oxidizing with $84.8 \%$ sequence identity; $M t$ LPMO9A, UniProt ID KP901251, C1/C4-oxidizing with 44.7\% sequence identity), Neurospora crassa (NcLPMO9F, UniProt ID Q1K4Q1, PDB ID 4QI8, strictly C1-oxidizing with $39.4 \%$ sequence identity; NcLPMO9C, UniProt ID Q7SHI8, PDB ID 4D7U, strictly C4-oxidizing with $47.2 \%$ sequence identity), and T. terrestris (TtLPMO9E, UniProt ID G2RGE5, PDB 3EJA, strictly C1-oxidizing with $43.9 \%$ sequence identity). The alignment (Fig. 1) and a structural model built using the structure of NcLPMO9C (PDB ID, 4D7U; Additional file 1, Fig. S1) show that the copper ion is coordinated by the fully conserved His1 and His79, whereas the fully conserved Tyr170 (at position 166 in Fig. 1) is also important for shaping the copperbinding site. Similarly to NcLPMO9C and MtLPMO9B, TausLPMO9B shows an insertion in the L3 region. The

\footnotetext{
(See figure on next page.)

Fig. 1 Amino acid sequence alignment of TausLPMO9B and other LPMOs. The LPMOs include: MtLPMO9A (MYCTH_85556; UniProt ID, G2QNT0), MtLPMO9B (MYCTH_80312; UniProt ID, G2QCJ3), TtLPMO9E (PDB ID, 3EJA; Uniprot ID, D0VWZ9), NcLPMO9C (PDB ID, 4D7U; Uniprot ID, Q7SHI8) and NCLPMO9F (PDB ID, 4QI8; Uniprot ID, Q1K4Q1). Fully conserved residues appear as white letters on red background. Residues that are highly conserved and share similar physico-chemical properties appear as red letters in blue squares. Residues involved in shaping the copper site, including the copper-binding histidine brace, are marked with blue asterisks. The secondary structure features indicated above the sequences are based on the NCLPMO9C structure [69] [ $\beta$-strands, arrows; a-helices, coils; turns, T]. The residue numbering applies to NcLPMO9C. Previously annotated regions of high sequence variability and with a dominating loop structure, named L2, L3, LS and LC [75], are indicated by red, blue, green and brown bars, respectively, below the sequences. The experimentally determined oxidative regioselectivities of the LPMOs (C1, C4, C1/C4) are indicated to the left. Digits and question marks below the sequence indicate cysteine residues involved in the formation of disulfide bridges; green digits apply to NCLPMO9C, purple digits mark the ones predicted for TausLPMO9B and purple question marks indicate additional cysteines in TausLPMO9B. ESPript was used to generate the figure [67]. The predicted N-glycosylation site is marked in an orange box
} 


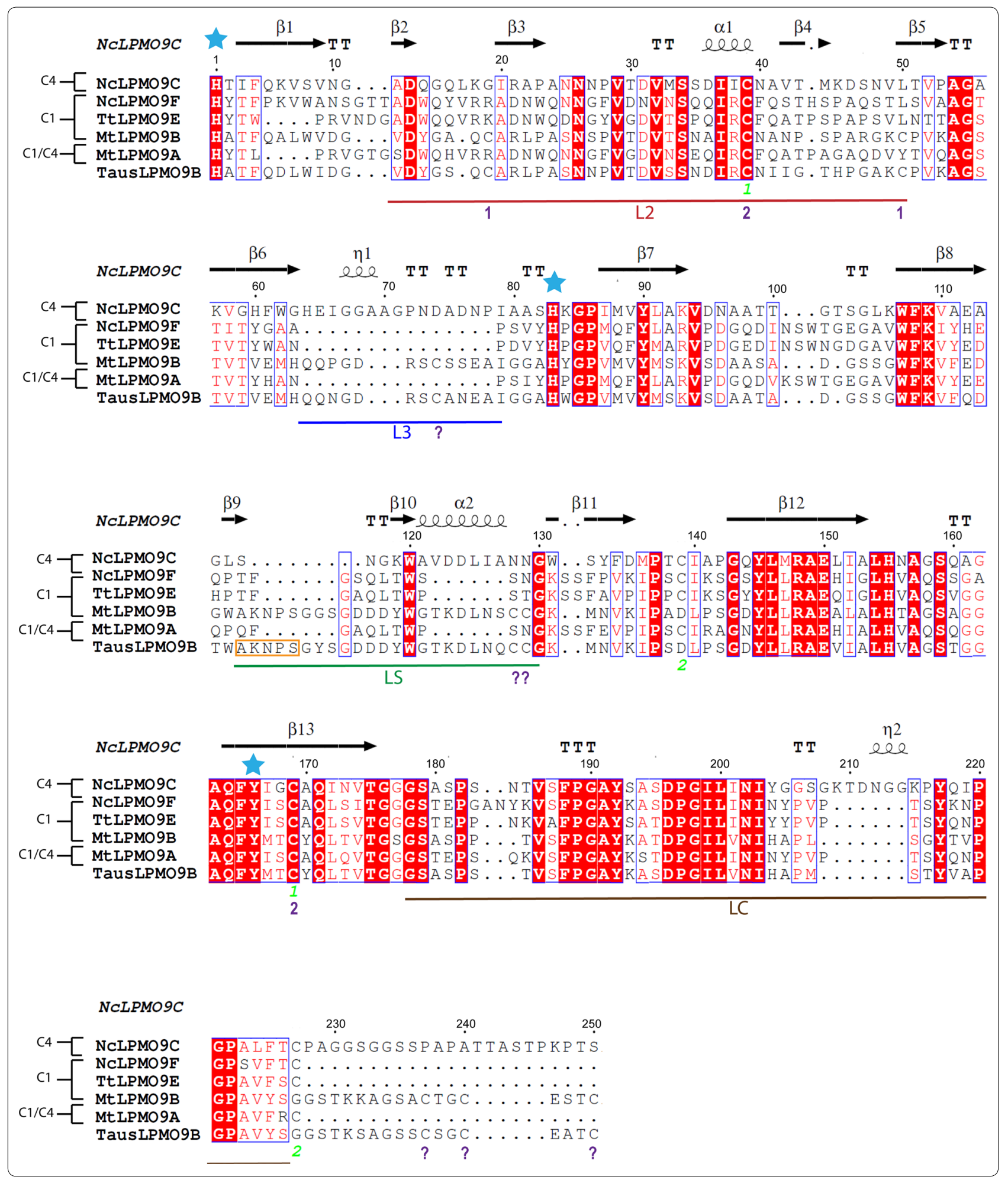

enzyme is predicted to have only one $N$-glycosylation site (Asn113) and 24 putative O-glycosylation sites, which are mostly located in the linker and CBM region.
Intriguingly, the complete amino acid sequence of TausLPMO9B contains 16 cysteines, an unusually high number, of which seven are predicted to be located in 
the AA9 catalytic domain (Cys18, 38, 49, 70, 132, 133 and 173), three are predicted to be part of the linker region adjacent to the AA9 domain (Cys233, 236 and 240) and six are present in the CBM1 module (Cys271, 279, 287, 290, 296 and 307) (Additional file 1, Table S1). The six Cys residues in the CBM1 module will expectedly form three disulfide bonds (Cys271-Cys287, Cys279-Cys296 and Cys290-Cys307) in the CBM1 domain as found in the CBM1 of the endoglucanase HjCel7B from $H$. jecorina (PDB ID, 4BMF). Notably, all ten Cys residues in the predicted AA9 and linker regions are conserved among a small group of AA9 LPMOs that include TausLPMO9B, the LPMOs listed in Table S2 in Additional file 1 (with 71-83\% identity; including $M t$ LPMO9B) as well as NcLPMO9E (UniProt ID, Q7RWN7) and NcLPMO9J (UniProt ID, Q7SHD9) from N. crassa and PaLPMO9B (UniProt ID, B2AVF1) from Podospora anserina (with $68-75 \%$ identity). While regioselectivity has been reported for several of these LPMOs, protein structure data are only available for LPMOs with low $(<50 \%)$ sequence identity that do not contain such a high number of Cys residues. (NcLPMO9C shares the highest, but only $47.2 \%$, sequence identity with TausLPMO9B and contains four Cys residues in the AA9 domain, two of which do not occur in TausLPMO9B.) Even in the absence of a protein structure, the fact that the three Cys residues located at the $\mathrm{N}$-terminal end of the linker region (within the first 17 amino acids) are conserved among this group of LPMOs strongly suggests that this part of the linker may have a strong interaction with the AA9 domain, likely forming disulfide bridges. In this respect, it is noteworthy that X-ray crystallographic studies have revealed close interactions between the $\mathrm{N}$-terminal, cysteine-free, part of the linker region of HjLPMO9A from Hypocrea jecorina (PDB ID, 5O2W) and its catalytic domain [43]. A closer look at the sequence alignment (Fig. 1 herein and Supplementary Figure S1 in reference [44]) reveals that the Cys39-Cys169 pair (Cys38-Cys173 in TausLPMO9B) comprises the only two Cys residues that are conserved in all AA9 LPMOs. In some AA9 LPMOs, including TausLPMO9B and MtLPMO9B, the L2 loop contains two Cys residues that are positioned such as to form a disulfide bond (positions 19 and 50 in Fig. 1; Cys18 and Cys49, respectively, in TausLPMO9B). The bonding status of the remaining three cysteines in TausLPMO9B, Cys70, Cys132 and Cys133 (positions 74, 128 and 129 in Fig. 1) is not known. It is worth noting that these positions are all surface located and that this is an odd number of cysteines, which may be taken to support the idea that the N-terminal part of the linker, which also contains an odd number (three) of cysteines, interacts with the catalytic domain. Laurent et al. have suggested that the cysteines at positions 74 and 129 form a disulfide bridge in $M t$ LPMO9B, which could pull the L3 loop away from the substrate-binding surface, perhaps creating a surface structure similar to that in (C1-oxidizing) LPMOs lacking the L3 insertion altogether [44].

\section{Protein expression, purification and mass spectrometry analysis}

TausLPMO9B was recombinantly produced in A. niger, with a yield of approximately $0.1 \mathrm{~g}$ protein per $\mathrm{L}$ culture. The protein was purified in a two-step protocol until about 95\% purity was obtained (Additional file 1: Fig. S2). A peptide map of the primary sequence was made after tryptic digestion, using LC-MS/MS. The peptide map covered $\sim 70 \%$ of the amino acid sequence and showed methylation of the $\mathrm{N}$-terminal peptide (Additional file 1: Table S3). The N-terminal peptide, residues $1-20$, was detected in both the methylated and non-methylated forms, and the data indicated that $91.7 \%$ of the N-terminus was methylated (Additional file 1: Fig. S3). The immonium ion of the methylated histidine was detected in the fragmentation spectrum of the methylated N-terminal peptide (Additional file 1: Fig. S4), confirming that the methylation occurred on the His1 and not on another amino acid in the $\mathrm{N}$-terminal peptide. The peptide containing the potential N-glycosylation site (residues 113127) was only detected in a form without attached sugars. Also, a parallel analysis of the tryptic digest of the protein after deglycosylation using PNGase F and Endo Hf showed no evidence of glycosylation on Asn113 (data not shown).

A profile of the mature proteoforms originating from varying covalent modifications was obtained by LC-MS analysis of the intact protein. For the deconvoluted MS spectrum of the main chromatographic peak, see Fig. S5 in Additional file 1. The theoretical molecular mass of the mature protein without any PTMs, but lacking the signal peptide, was predicted to be $31,355 \mathrm{Da}$. The potential PTMs include formation of disulfide bridges $(\Delta m / z=-$ 2; 16 cysteines in total, so maximally -16$)$, methylation of the N-terminal histidine $(\Delta m / z=+14)$ and $O$-glycosylation $(\Delta m / z=+162$ per hexose unit). The deconvoluted mass spectrum of the main chromatographic peak (Additional file 1: Fig. S5) shows a distribution of proteoforms with mass increments of $\Delta m / z=162.14$, indicative of heterogenous glycosylation reflected in a varying number of attached hexoses. The lowest, clearly distinguishable, mass in the deconvoluted mass spectrum was $m / z=33,136\left[\mathrm{M}+\mathrm{H}^{+}\right]$, indicating heavy $O$-glycosylation of TausLPMO9B. The observed difference between the expected $\left(m / z=31,356\left[\mathrm{M}+\mathrm{H}^{+}\right]\right)$and observed masses (from $m / z=33,136$ to $m / z=37,677\left[\mathrm{M}+\mathrm{H}^{+}\right]$with mass increments of $\Delta m / z=162$; Fig. S5 in Additional file 1) 

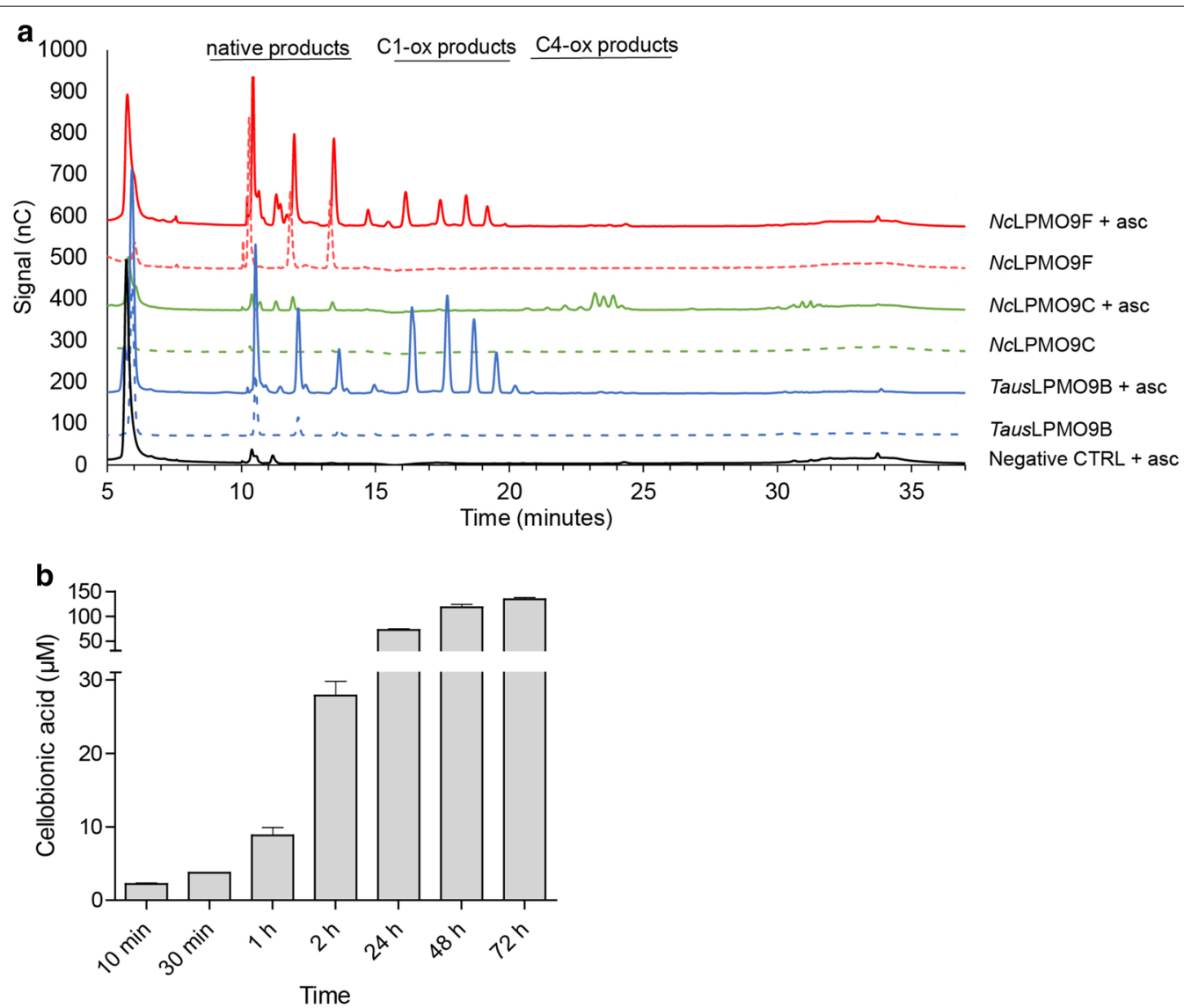

Fig. 2 Activity of TausLPMO9B on PASC. a HPAEC-PAD chromatogram for products released after $24 \mathrm{~h}$ incubation at $45^{\circ} \mathrm{C}$, $\mathrm{pH} 5.0$, in the presence (continuous line) or absence (dotted line) of $1 \mathrm{mM}$ ascorbic acid (TausLPMO9B chromatograms are shown in blue, NCLPMO9C in green, NCLPMO9F in red, and the negative control in black). The reactions contained $0.1 \%(\mathrm{w} / \mathrm{v})$ PASC and $1 \mu \mathrm{M}$ enzyme. b Accumulation of cellobionic acid over time in a reaction with $1 \mu \mathrm{M}$ TausLPMO9B, 0.1\% (W/V) PASC and $1 \mathrm{mM}$ ascorbic acid. Cellobionic acid release by TausLPMO9B was quantified by intrapolation of the integrated peak area of the C1-oxidized dimer with a standard curve of cellobionic acid standard solutions (10-50 $\mu \mathrm{M})$. (Note that cellobionic acid corresponds to only a fraction of the LPMO products as longer C1-oxidized cello-oligosaccharides were not converted to dimers before HPAEC-PAD analysis)

suggests a range of 11-39 hexoses on the most abundant proteoforms of TausLPMO9B.

\section{Substrate specificity and regioselectivity on cellulose}

TausLPMO9B was incubated with PASC to monitor its activity over time and determine its regioselectivity, in the presence of ascorbic acid as electron donor. As positive controls, C1-oxidizing NcLPMO9F and C4-oxidizing NcLPMO9C [45] were incubated under the same conditions. C4-oxidized products could be detected for the reactions driven by $N c L P M O 9 C$, while $N c L P M O 9 F$ and TausLPMO9B only released C1-oxidized products (Fig. 2a). Monitoring of the accumulation of oxidized products over time showed that under the conditions tested $\left(\mathrm{pH} 5,45^{\circ} \mathrm{C}\right)$ the enzyme was highly active for at least $24 \mathrm{~h}$ (Fig. 2b). While experimental data show that, similarly to its closest homologue MtLPMO9B, TausLPMO9B is a strictly C1-oxidizing LPMO, it is not yet fully clear which structural features determine the stereospecificity of LPMOs [46, 47]. Earlier studies correlated the presence of an insertion in the L3 region with a preferential C4-oxidizing activity [48]. More recently, Laurent et al. showed that this type of insertion, which they refer to as Segment 2, is not always associated with strictly C4-oxidizing activities [44], as is corroborated by the data presented here for TausLPMO9B. A phylogenetic tree analysis revealed that, indeed, TausLPMO9B clustered with other C1-oxidizing LPMOs (Fig. S6 in Additional file 1). This confirms other recent studies showing that identifying local pairwise alignments in the phylogenetic tree is a better approach, as it is not yet clear which are the structural features determining LPMOs' stereospecificity [49]. Of note, there are more examples of discrepancies between predicted and observed regioselectivities. In 2015, Bennati et al. showed that PaLP$\mathrm{MO} 9 \mathrm{H}$, predicted to be a C4-oxidizing LPMO, was 
actually producing $\mathrm{C} 1-$ and C4-oxidized products [50]. Before this, biochemical characterization of MtPMO3* (MYCTH_92668) resulted in its classification as a C1-oxidizing LPMO despite its predicted C1/C4-oxidizing regioselectivity [48]. Taken together, these examples highlight that more biochemical and structural data are needed to determine, predict and understand the structural determinants of regioselectivity.

Similarly to $M t$ LPMO9B [19], no oxidized products were detected upon incubation with hemicellulosic substrates, such as $\beta$-glucan, glucomannan, arabinoxylan, xyloglucan, xylan (alone and in combination with PASC; Additional File 1: Fig. S7), and soluble oligosaccharides, such as cellopentaose.

The presence of reductant is key for the LPMO reaction, and the efficiency of different reductants to drive the reaction varies between LPMOs [19]. Differences are caused by many aspects, including the reactivity of the reductant with $\mathrm{O}_{2}$ and dependency on $\mathrm{pH}[51,52]$. As for reactions with biomass, it is well known that lignin and/ or lignin-derived compounds may act as reductant and that addition of an external reductant may be needed in cases where the pretreatment of biomass drastically decreases the lignin content $[10,21,53,54]$. Frommhagen et al. determined reductant preferences for $M t \mathrm{LPMO} 9 \mathrm{~B}$ from $M$. thermophila, the AA9 domain of which shares 83.9\% identity with TausLPMO9B [19]. Inspired by this previous work, we tested compounds containing either sulfur (L-cysteine), a benzenediol moiety (L-DOPA) or a benzenetriol moiety (gallic acid), since these all had a positive effect on $M t$ LPMO9B [19]. In addition, commercial lignin, as well as the water-soluble lignin extracted from acid pretreated corn stover, were tested. Similarly to what was observed for $M t$ LPMO9B, L-DOPA and ascorbic acid were the most efficient reductants driving TausLPMO9B activity, leading to the release of a higher amount of oxidized products after $24 \mathrm{~h}$ (Fig. 3).

\section{Thermal stability and $\mathrm{pH}$ dependency of TausLPMO9B}

The effects of $\mathrm{pH}$ and temperature on the activity of TausLPMO9B were investigated using PASC as substrate. Under the conditions tested, TausLPMO9B released the highest amount of oxidized products in the range of $35-45{ }^{\circ} \mathrm{C}$ (Fig. 4a). The apparent enzyme activity was drastically reduced at higher temperatures (Fig. 4a), which was surprising considering the fact that protein stability measurements with the Thermofluor assay (Table 1 and Fig. S8 in Additional file 1) indicated an apparent melting temperature around $75^{\circ} \mathrm{C}$. It is likely that under the conditions used here, the thermal stability of the reducing agent ascorbic acid and/

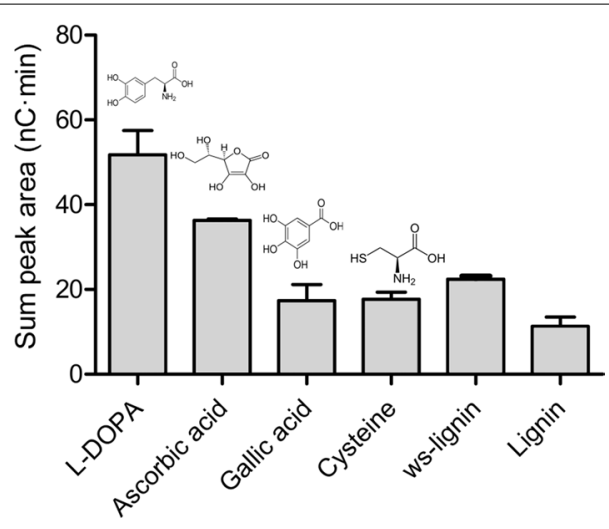

Fig. 3 Activity of TausLPMO9B in the presence of various reductants. The graph shows the release of oxidized products by Taus LPMO9B in reactions with different reductants. The chemical structures of the reductants are indicated above the bars. Reactions contained $1 \mu \mathrm{M} \mathrm{LPMO}, 0.1 \%(\mathrm{w} / \mathrm{v})$ PASC and either $1 \mathrm{mM}$ of small reducing compounds, $1 \mathrm{mg} / \mathrm{mL}$ of kraft lignin or $1 \%(\mathrm{v} / \mathrm{v})$ of water-soluble lignin (ws-lignin). Product release was measured after 24 -h incubation at $45^{\circ} \mathrm{C}$ and $\mathrm{pH} 5.0$ and is reported as the sum of the area of peaks corresponding to C1-oxidized cello-oligosaccharides (DP2-DP6). Due to the high background signal of the extracted lignin (ws-lignin) overlapping with signals of the LPMO products, the results for this set of experiments were background corrected. In the control sample, PASC was incubated with ws-lignin but without enzymes, using the same reaction conditions as in the reaction containing the enzyme.

Reactions were run in triplicate, error bars indicate standard deviation

or limited solubility of oxygen at increased temperatures $[19,51,52,55]$ may have come into play. Almost no products were detected after $24 \mathrm{~h}$ of incubation at $85^{\circ} \mathrm{C}$.

Next, we assessed the effect of $\mathrm{pH}$ on TausLPMO9B activity. It should be noted that the $\mathrm{pH}$ has an indirect impact on LPMO product formation due to the $\mathrm{pH}$ dependency of the reducing capacity of the reducing agent (i.e., ascorbic acid) [51, 52]. Under the conditions used here, the enzyme released most oxidized products at a $\mathrm{pH}$ between 4 and 6 , with the highest level detected at $\mathrm{pH} 5$ (Fig. 4b). As most of the industrial cellulolytic enzymes have an optimum around $\mathrm{pH}$ 5 [56], this makes TausLPMO9B, under the tested conditions, highly suitable to complement such enzymes. To assess the stability of TausLPMO9B at different $\mathrm{pH}$ conditions, the enzyme was pre-incubated in buffer at a $\mathrm{pH}$ ranging from 3.0 to 8.0 for $24 \mathrm{~h}$ at $45^{\circ} \mathrm{C}$. Comparison of the initial and residual activities of the enzyme, based on the formation of oxidized products released from PASC in a $24-\mathrm{h}$ reaction at $45^{\circ} \mathrm{C}$ at the $\mathrm{pH}$ of the pre-incubation (Fig. 4c), revealed some loss of activity at $\mathrm{pH}$ 3. Protein stability measurements using the Thermofluor assay confirmed that TausLPMO9B was significantly less stable at $\mathrm{pH} 3.0$ (apparent $T_{\mathrm{m}}$ of $61^{\circ} \mathrm{C}$ at 

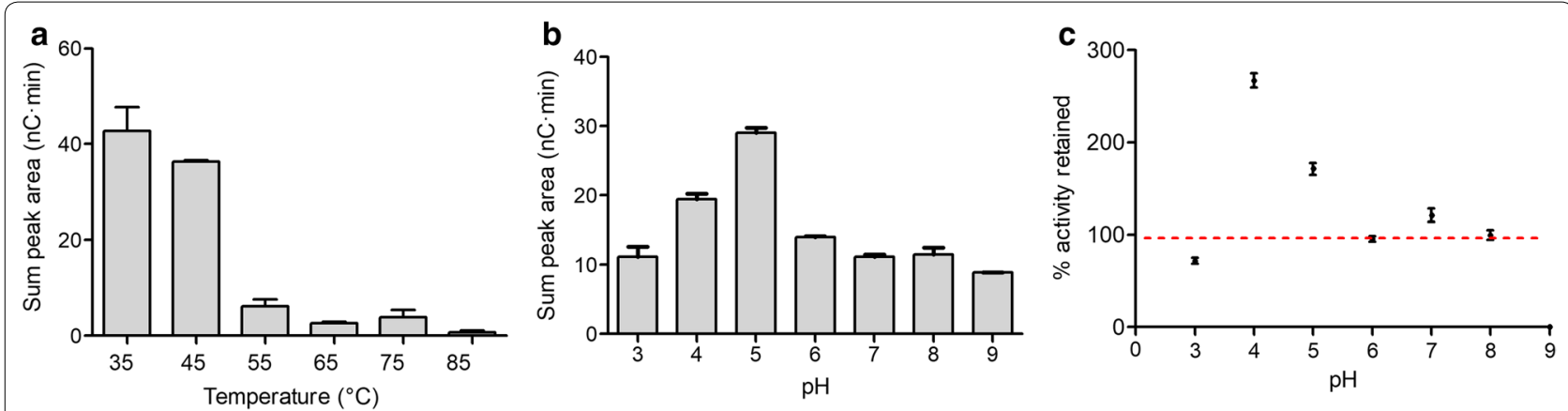

Fig. 4 Effect of temperature and pH on TausLPMO9B. Reaction mixtures containing 1- $\mu M$ LPMO, 1-mM ascorbic acid and $0.1 \%$ W/v PASC were incubated for $24 \mathrm{~h}$ at different conditions: a fixed $\mathrm{pH}$ 5.0, different temperatures $\left(35^{\circ} \mathrm{C}, 45^{\circ} \mathrm{C}, 55^{\circ} \mathrm{C}, 65^{\circ} \mathrm{C}, 75^{\circ} \mathrm{C}\right.$ and $\left.85^{\circ} \mathrm{C}\right)$; $\mathbf{b}$ fixed temperature $45^{\circ} \mathrm{C}$, different pHs (3.0, 4.0, 5.0, 6.0, 7.0, 8.0 and 9.0). The amount of total oxidized products was calculated as sum of the peak areas of peaks eluting between 16 and 30 min during HPAEC-PAD (i.e., C1-oxidized cello-oligosaccharides, DP2 - DP6). The stability of TausLPMO9B in the function of pH (c) was evaluated by pre-mixing the enzyme with buffers of varying $\mathrm{pH}$ in $50 \%$ of the final reaction volume and incubating for $24 \mathrm{~h}$ at $45^{\circ} \mathrm{C}$, after which PASC $(0.1 \% \mathrm{w} / \mathrm{v})$ and ascorbic acid $(1 \mathrm{mM})$ were added to initiate the reaction, followed by incubation for $24 \mathrm{~h}$ at $45^{\circ} \mathrm{C}$. Control reactions at the same varying $\mathrm{pH}$ values but without the pre-incubation step were also set up. The data points represent the percentage of activity retained by the pre-incubated enzyme, relative to the non-pre-incubated enzyme. Activities were calculated as the sum of peak areas corresponding to oxidized products in the HPAEC-PAD analysis. In other words, 100\% retained activity (marked by a red line) means that the amount of oxidized products released was identical in the reactions with and without pre-incubation

Table 1 The effect of $\mathrm{pH}$ on the apparent melting temperature $\left(T_{m}\right)$ of TausLPMO9B

\begin{tabular}{ll}
\hline pH & $\begin{array}{l}\text { Melting } \\
\text { temperature } \\
\left({ }^{\circ} \mathbf{C}\right)\end{array}$ \\
\hline 3 & $61.2 \pm 0.7$ \\
5 & $76.3 \pm 0.3$ \\
7 & $75.8 \pm 0.5$ \\
8 & $74.5 \pm 0.4$ \\
\hline
\end{tabular}

$\mathrm{pH}$ 3.0) than at $\mathrm{pH} 5.0-8.0$ (apparent $T_{\mathrm{m}}$ around $75^{\circ} \mathrm{C}$ ) (Table 1 and Fig. S8 in Additional file 1).

Melting temperatures were measured at different $\mathrm{pH}$ values using the Thermofluor assay, as described in the legend of Fig. S8 in Additional file 1, which shows raw data. The analyses were run in triplicates; errors correspond to standard deviations.

While TausLPMO9B proved to be a rather stable enzyme at all tested $\mathrm{pH}$ values, we observed an intriguing increase in LPMO activity upon overnight preincubation of the enzyme at $\mathrm{pH} 4.0$ and 5.0 (Fig. 4c), for which we currently do not have an explanation. It is clear though from the above observation that optimal conditions for studying the biochemical properties and industrial applicability of TausLPMO9B entail a $\mathrm{pH}$ of around 5 and a temperature of $45^{\circ} \mathrm{C}$.

\section{The role of $\mathrm{H}_{2} \mathrm{O}_{2}$ as a co-substrate}

As recent studies reported that LPMOs are more efficient when fueled with $\mathrm{H}_{2} \mathrm{O}_{2}$ as co-substrate instead of
$\mathrm{O}_{2}[18,28,57,58]$, we assessed the suitability of $\mathrm{H}_{2} \mathrm{O}_{2}$ as co-substrate for TausLPMO9B. First, PASC was incubated with TausLPMO9B, $\mathrm{H}_{2} \mathrm{O}_{2}$ and an excess of reductant (1-mM ascorbic acid). Under the studied conditions, supplementing the reaction with $\mathrm{H}_{2} \mathrm{O}_{2}$ (at 25-200 $\mu \mathrm{M}$ concentration) had a positive impact on the initial rate of product formation, while higher concentrations of $\mathrm{H}_{2} \mathrm{O}_{2}$ (here 100-200 $\mu \mathrm{M}$ ) were detrimental for the enzyme and led to an early stop of product accumulation (Fig. 5a). Our results are in agreement with previous studies showing that low concentrations of $\mathrm{H}_{2} \mathrm{O}_{2}$ are able to boost LPMO activity, while an excess of $\mathrm{H}_{2} \mathrm{O}_{2}$ leads to inactivation of the enzyme, presumably through oxidative damage, due to the fact that the non-substrate-bound fraction of reduced LPMOs will react with $\mathrm{H}_{2} \mathrm{O}_{2}$ and catalyze selfinactivation [18]. Figure 5b shows a negative correlation between the amount of $\mathrm{H}_{2} \mathrm{O}_{2}$ supplied to the reaction and product levels obtained after 24-h incubation; reactions with added $\mathrm{H}_{2} \mathrm{O}_{2}$ yielded less oxidized cello-oligosaccharides than those where $\mathrm{H}_{2} \mathrm{O}_{2}$ was not added. At this high ascorbic acid concentration and in the absence of added $\mathrm{H}_{2} \mathrm{O}_{2}$, the reaction may be slower but proceeds for a much longer time, leading to the highest product levels. In the reactions with added $\mathrm{H}_{2} \mathrm{O}_{2}$, multiple deleterious effects may occur, including direct autocatalytic inactivation of the enzyme, as mentioned above, and reactions between the reductant and $\mathrm{H}_{2} \mathrm{O}_{2}$, which reduces the concentration of both and may generate potentially damaging reactive oxygen species.

To further elucidate the role of $\mathrm{H}_{2} \mathrm{O}_{2}$ in the action of TausLPMO9B, we reduced the concentration of ascorbic 

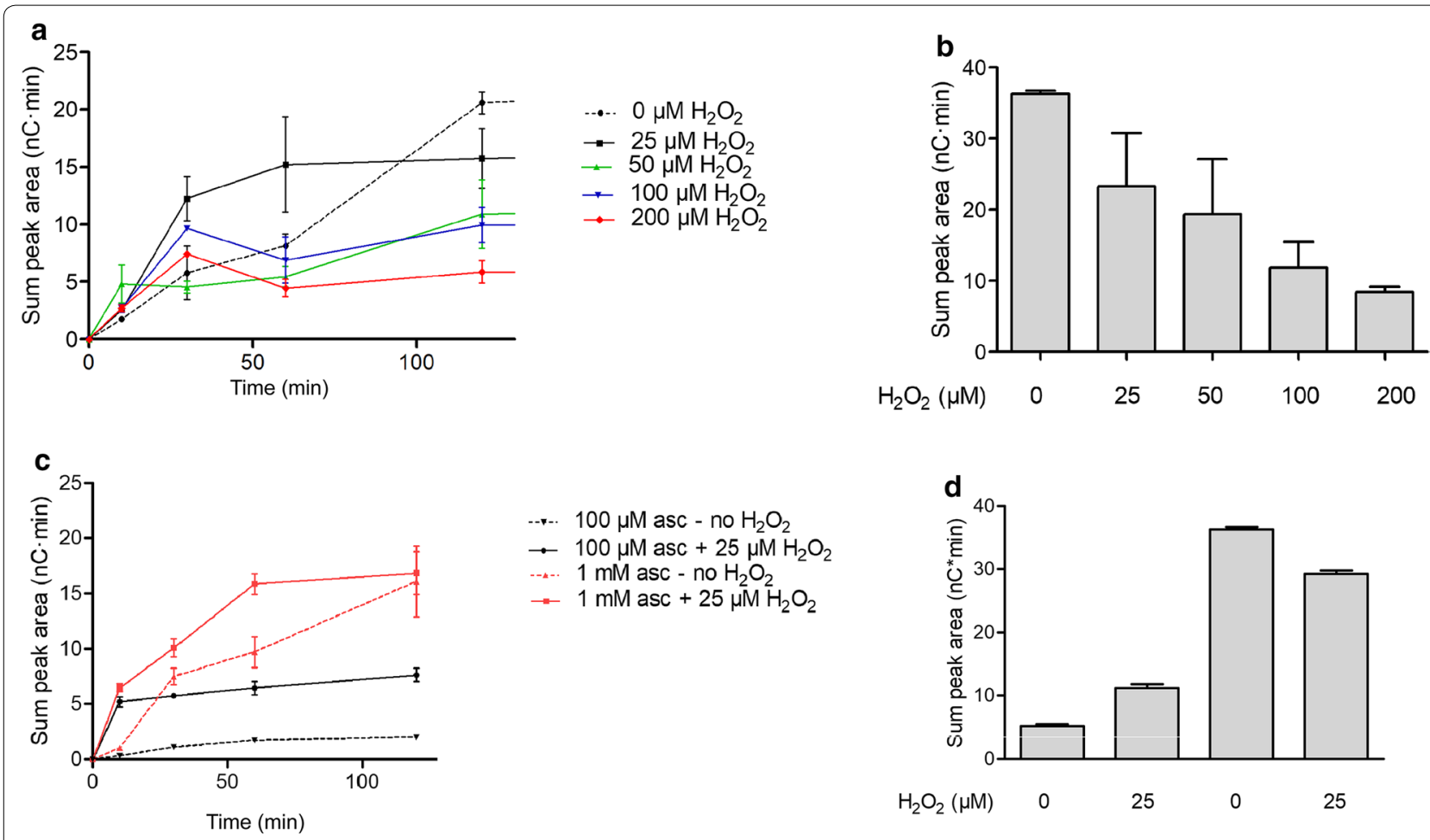

Fig. 5 Effect of $\mathrm{H}_{2} \mathrm{O}_{2}$ and ascorbic acid on TausLPMO9B activity on cellulose. 0.1\% (w/v) PASC was incubated with 1- $\mu M$ TausLPMO9B acid in sodium acetate buffer $\mathrm{pH} 5.0$ at $45^{\circ} \mathrm{C}$ with different combinations of reductant $/ \mathrm{H}_{2} \mathrm{O}_{2} \cdot \mathbf{a}, \mathbf{b}: 1-\mathrm{mM}$ ascorbic acid and supplementation of different concentrations of $\mathrm{H}_{2} \mathrm{O}_{2}(0-200 \mu \mathrm{M})$. At time ' 0 ', the reactions were supplemented with 0-200 $\mu \mathrm{M} \mathrm{H}_{2} \mathrm{O}_{2}$. Product formation was assessed based on the sum of peak areas corresponding to C1-oxidized cello-oligosaccharides in the HPAEC-PAD chromatograms. c, d 0.1\% (W/V) PASC was incubated with $1 \mu \mathrm{M}$ TausLPMO9B and either $100-\mu \mathrm{M}$ or 1-mM ascorbic acid in sodium acetate buffer $\mathrm{pH} 5.0$ at $45^{\circ} \mathrm{C}$. At time ' 0 ', the reactions were supplemented with $\mathrm{O}$ (ultra pure water) or $25-\mathrm{\mu M} \mathrm{H}_{2} \mathrm{O}_{2}$. Product formation was assessed based on the sum of peak areas corresponding to C1-oxidized cello-oligosaccharides in the HPAEC-PAD chromatograms. a, c Product accumulation in the first 120 min, the lines connecting the points are drawn for illustration purposes only; $\mathbf{b}, \mathbf{d}$ final product levels after $24 \mathrm{~h}$. The error bars indicate standard deviations of three replicates

acid in the reaction to $100 \mu \mathrm{M}$, which is in line with the hypothesis that, to perform their oxidative reaction using $\mathrm{H}_{2} \mathrm{O}_{2}$, LPMOs would only require low amounts of reductant [18]. In this setup, the effect of adding $\mathrm{H}_{2} \mathrm{O}_{2}$ was much more pronounced. Adding only $25-\mu \mathrm{M} \mathrm{H} \mathrm{H}_{2} \mathrm{O}_{2}$ to the reaction mixture with $100-\mu \mathrm{M}$ ascorbic acid led to a 16 -fold increase in product formation after $10 \mathrm{~min}$ (Fig. 5c) and a twofold increase in the overall product yield after $24 \mathrm{~h}$ (Fig. $5 \mathrm{~d}$ ). Under these conditions, there is $\sim 190-\mu \mathrm{M} \mathrm{O}_{2}$ present [55] and 25- $\mu \mathrm{M} \mathrm{H}_{2} \mathrm{O}_{2}$, suggesting that the affinity of TausLPMO9B for $\mathrm{H}_{2} \mathrm{O}_{2}$ is higher than for $\mathrm{O}_{2}$, leading to a faster initial activity. These findings corroborate earlier studies showing that $\mathrm{H}_{2} \mathrm{O}_{2}$ is utilized preferentially by LPMOs compared to $\mathrm{O}_{2}[18,28]$. The best performance over $24 \mathrm{~h}$ was achieved without $\mathrm{H}_{2} \mathrm{O}_{2}$ addition, using higher amounts of reductant in the presence of oxygen (Fig. 5d). A plausible explanation for this could be that, in the presence of ascorbic acid and molecular $\mathrm{O}_{2}, \mathrm{H}_{2} \mathrm{O}_{2}$ is formed slowly and steadily, driving the enzyme reaction [18]. In this manner, $\mathrm{H}_{2} \mathrm{O}_{2}$ concentrations would never become high (likely never above a few micromolar $[28,54])$, which avoids enzyme damage. These observations suggest that it would be better to drive the enzyme reaction with the help of an enzymatic redox partner producing $\mathrm{H}_{2} \mathrm{O}_{2}$ in situ, such as cellobiose dehydrogenase [59], rather than with externally supplied $\mathrm{H}_{2} \mathrm{O}_{2}$. Such enzymes are abundant in fungal secretomes [58].

\section{Hydrolysis of pretreated corn stover}

To examine the potential of TausLPMO9B to enhance the performance of classic hydrolytic cellulase cocktails, like Celluclast $^{\circledR}$, during the saccharification of industrially relevant lignocellulosic material using oxygen (supplied as air) or $\mathrm{H}_{2} \mathrm{O}_{2}$ as co-substrate, hydrolysis experiments with acid pretreated corn stover were performed. To simulate industrial processing, reactions were carried out in 1.5-L fermenters where the composition of the headspace could be controlled to ensure aerobic or anaerobic conditions and the stirring power allowed proper mixing 
of $10 \%(\mathrm{w} / \mathrm{w})$ dry matter slurries. The boosting effect of TausLPMO9B was tested via spiking a cellulase cocktail (BG-enriched Celluclast ${ }^{\circledR}$ ) with the LPMO both in the presence and absence of oxygen (supplied as air) or $\mathrm{H}_{2} \mathrm{O}_{2}$. Based on previous studies using different dosages of $\mathrm{H}_{2} \mathrm{O}_{2}[18,54]$ and taking into consideration possible side reactions of $\mathrm{H}_{2} \mathrm{O}_{2}$ with feedstock components [23], it was decided to spike $100-200 \mu \mathrm{M} \mathrm{H}_{2} \mathrm{O}_{2}$ three times per day to the bioreactors, to ensure sufficient supply of hydrogen peroxide. In total, six bioreactors were set up: three containing BG-enriched Celluclast ${ }^{\circledR}$ and three containing BG-enriched Celluclast ${ }^{\circledR}$ spiked with LPMO. The saccharification reactions with and without LPMO were carried out under aerobic conditions (oxygen supplied via headspace sparging with air) (Fig. 6a) and anaerobic conditions (headspace sparging with $\mathrm{N}_{2}$ ), the latter of which was without or with spiking of $\mathrm{H}_{2} \mathrm{O}_{2}$ (Fig. 6b, c, respectively).

The results showed that addition of TausLPMO9B was able to improve the initial rate of glucan conversion by the Celluclast ${ }^{\circledR} / \mathrm{BG}$ mixture in the presence of oxygen (Fig. 6a). This is in agreement with earlier observations showing the ability of LPMO to boost the conversion of lignin-containing feedstocks in the presence of oxygen $[21,53,54]$. As expected, the LPMO effect could not be detected in saccharification reactions operated under anaerobic conditions (Fig. 6b). Furthermore, in contrast to the assays performed on PASC at small scale without $\mathrm{pH}$ and aeration controls (see Fig. 5), addition of $\mathrm{H}_{2} \mathrm{O}_{2}$ had no significant effect on the outcome of the saccharification reaction, indicating that under these anaerobic conditions, the LPMO stayed inactive (Fig. 6c). We propose that the lack of the effect of $\mathrm{H}_{2} \mathrm{O}_{2}$ is due to the presence of lignin, which may react with $\mathrm{H}_{2} \mathrm{O}_{2}$ before the LPMO can use it as a co-substrate.

So far, only a handful of studies have been conducted to address the effect of $\mathrm{H}_{2} \mathrm{O}_{2}$ additions on the efficiency of the saccharification of different types of biomass with LPMO-containing enzyme cocktails [18, 54]. Comparing the saccharification of Avicel and two types of industrially relevant biomasses (sulfite-pulped Norway spruce and steam-exploded birch), the seminal study by Müller et al. [54] showed that the presence of lignin in the biomass decreased the efficiency with which the LPMO was able to use externally supplied $\mathrm{H}_{2} \mathrm{O}_{2}$. In agreement with this, a recent study by Kont et al. [23] has shown that lignin has both $\mathrm{H}_{2} \mathrm{O}_{2}$-forming and -scavenging activities and suggested that $\mathrm{H}_{2} \mathrm{O}_{2}$ is an intermediate of lignin oxidation. Hence, it is plausible that lignin reacts with the supplied $\mathrm{H}_{2} \mathrm{O}_{2}$ before it reaches the LPMO. Potentially, this could lead to generation of reactive oxygen species that may contribute to inactivation of LPMOs and other enzymes in the reaction. While there are several indications in literature that lignin is important for driving LPMO action on industrial substrates in the presence of $\mathrm{O}_{2}[20,24,53]$, the type of substrate, its pretreatment and, hence, its composition will affect the ability of LPMOs to use externally supplied $\mathrm{H}_{2} \mathrm{O}_{2}$ as a co-substrate (this study; [54]).

\section{Discussion}

The number of LPMOs in (thermophilic) filamentous fungi and their expression levels vary to a great extent. The genome of T. terrestris, for example, encodes nearly 20 AA9 LPMOs [60]. T. aurantiacus, on the other hand, encodes only a handful of AA9 LPMOs in their genome [61]. Here, we report the characterization of TausLPMO9B from the thermophilic fungus T. australiensis and describe its potential to use $\mathrm{O}_{2}$ and $\mathrm{H}_{2} \mathrm{O}_{2}$ as co-substrate in reactions on both model and industrial substrates. TausLPMO9B was found stable at slightly acidic $\mathrm{pH}$ and active on lignocellulosic feedstocks, such as acid pretreated corn stover, indicative of its potential suitability for supplementing today's commercial cellulase cocktails for biomass saccharification. The efficiency of the enzyme was dependent on the type of cellulosic substrates; on "clean" model celluloses, addition of $\mathrm{H}_{2} \mathrm{O}_{2}$ promoted faster initial activity and, in some cases, a higher final product yield; whilst on industrially relevant lignocellulosic materials, reactions running in the presence of $\mathrm{O}_{2}$ only led to a faster overall saccharification. As the lignin may react with the added $\mathrm{H}_{2} \mathrm{O}_{2}$ [23] and, thus, limits the availability of $\mathrm{H}_{2} \mathrm{O}_{2}$ for the LPMO, it would be interesting to investigate other options for its supply. An interesting option would be the use of auxiliary enzymes, such as cellobiose dehydrogenases $(\mathrm{CDH})$. Kracher et al. have demonstrated that LPMO reactions fueled by an engineered $\mathrm{CDH}$ with increased oxidase activity are faster and more steady, due to a higher $\mathrm{H}_{2} \mathrm{O}_{2}$ production rate compared to the wild-type enzyme [59]. It might be useful to use both LPMOs and $\mathrm{H}_{2} \mathrm{O}_{2}$-generating enzymes that contain CBMs, since this could assure that $\mathrm{H}_{2} \mathrm{O}_{2}$ is being generated close to the substrate and the LPMO, which could reduce side reactions of $\mathrm{H}_{2} \mathrm{O}_{2}$ with lignin [62].

For the characterization of the properties of TausLPMO9B, commonly applied reaction setups were used wherein the reaction is driven by oxidation of the reductant, in most cases ascorbic acid, either by direct reactions with $\mathrm{O}_{2}$, or by reactions involving the LPMO. If one accepts the increasingly supported notion that $\mathrm{H}_{2} \mathrm{O}_{2}$ is a kinetically more relevant co-substrate of LPMOs $[18,28,31]$, the reactions carried out here (and in many previous studies) may be limited by in situ generation of $\mathrm{H}_{2} \mathrm{O}_{2}$ rather than by the catalytic ability or stability of the LPMO. Observed differences in reductant efficiency could relate to the generation of hydrogen peroxide 

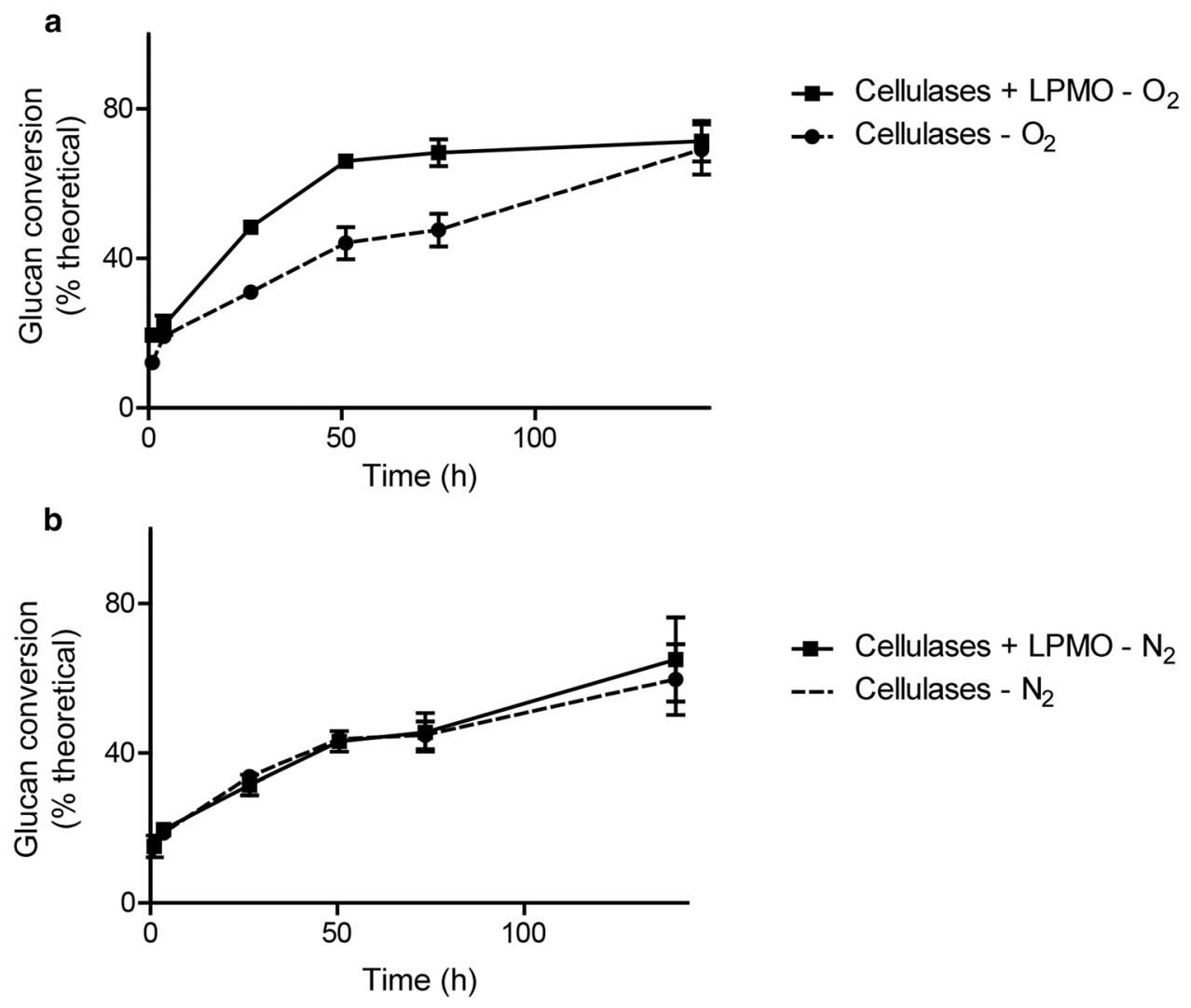

- Cellulases + LPMO $-\mathrm{N}_{2}$
-- Cellulases $-\mathrm{N}_{2}$

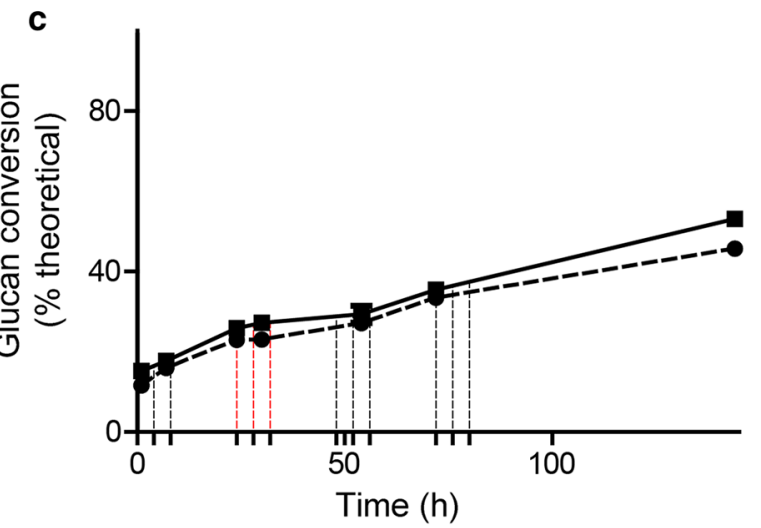

$\rightarrow$ Cellulases + LPMO - $\mathrm{H}_{2} \mathrm{O}_{2}-\mathrm{N}_{2}$

$\rightarrow$ Cellulases $-\mathrm{H}_{2} \mathrm{O}_{2}-\mathrm{N}_{2}$

- $100 \mu \mathrm{M} \mathrm{H} \mathrm{H}_{2}$ addition

- $200 \mu \mathrm{M} \mathrm{H} \mathrm{H}_{2}$ addition

Fig. 6 Effect of TausLPMO9B in hydrolysis of acid pretreated corn stover (PCS). PCS at 10\% DM (w/v) was incubated in bioreactors with a mixture of Celluclast ${ }^{\circledR}-\mathrm{BG}$, with (continuous line) or without (dotted line) additional LPMO under different conditions: a constant sparging of headspace with air, $\mathbf{b}$ constant sparging with $\mathrm{N}_{2}$, and c constant sparging with $\mathrm{N}_{2}$, with the addition of $\mathrm{H}_{2} \mathrm{O}_{2}$ three times a day to a final concentration of $100 \mu \mathrm{M}$ (black dotted lines) or $200 \mu \mathrm{M}$ (red dotted lines) per addition. The dosage was increased as no clear effect was detectable on the glucose release levels after the first three dosages. Samples were collected at different time points and enzymes were immediately inactivated by addition of 4-N $\mathrm{NaOH}$. Glucose was quantified by HPLC. The error bars indicate standard deviations of two replicates

rather than to the ability to reduce the LPMO. Moreover, factors such as $\mathrm{pH}$ and temperature will affect important reaction parameters next to the catalytic activity of the LPMO, including the level of dissolved oxygen and the oxidative stability of the reductant, which, together, will affect the formation of $\mathrm{H}_{2} \mathrm{O}_{2}$. Therefore, it cannot be excluded that reactions driven by gradual supply of appropriate amounts of $\mathrm{H}_{2} \mathrm{O}_{2}$ would yield other $\mathrm{pH}$ or temperature optima, or even substrate specificities, although existing data indicate that the latter does not vary between $\mathrm{O}_{2}$ - and $\mathrm{H}_{2} \mathrm{O}_{2}$-driven reactions [33]. 


\section{Conclusions}

Since the discovery of their ability to boost saccharification of lignocellulosic material only a decade ago, LPMOs have been the object of intense research to harvest their full potential in enzymatic saccharification. Unfortunately, in industrially relevant settings (i.e., $15-20 \% \mathrm{w} / \mathrm{w}$ pretreated biomass, containing much more than only cellulose), assessing LPMO activity is rather challenging because a high background from compounds present in the pretreated feedstock makes detection of LPMOderived oxidized reaction products challenging. Detection and identification of LPMO products require, most of the time, the use of "clean" model substrates such as Avicel or PASC. It has previously been shown that the observed activity of LPMOs on "real" feedstocks differs from the results obtained with model substrates [54]. It has also been shown that harnessing the full potential of the enzyme requires a delicate balancing act between activation, the presence of co-substrates $\left(\mathrm{O}_{2}\right.$ or $\left.\mathrm{H}_{2} \mathrm{O}_{2}\right)$ and inactivation $[18,28]$.

Our present findings corroborate the notion that the current parameters used in industrial-scale saccharification remain to be optimized to leverage LPMO performance on lignin-rich substrates to the same extent as what can be achieved with "cleaner" substrates. Since the impact of LPMOs on biomass saccharification is considerable and indisputable, further research on the redox processes that happen in reactions with real biomass is of major interest.

\section{Methods}

\section{Production and purification of enzymes}

The gene encoding for TausLPMO9B was PCR amplified from a cDNA library of T. australiensis strain ATCC 28,236 and expressed in A. niger. In short, the TausLPMO9B gene (sequence ID number 1 in reference 34 ) was PCR amplified using the forward primer 5'-CCC CAGCAACAAAACACCTCAGCAATGAAGTCGTTC ACCGTTGCC-3', the reverse primer $5^{\prime}$-GAAGGACGG CGACGGACTTCAGATACACTGGTAGTAGTAAAG G-3' and a proofreading DNA polymerase (Phusion DNA Polymerase) according to the suppliers' instructions (Finnzymes). Also, the expression vector pGBFIN-49 [63] was PCR amplified using the forward primer $5^{\prime}$-GTCCGTCGCCGTCCTTCACCG-3' ${ }^{\prime}$ and the reverse primer 5 -GGTGTTTTGTTGCTGGGGATGAAG C-3'. After ligation-independent cloning (LIC) according to Aslanidis et al. [64], TausLPMO9B was cloned in between the $A$. niger glaA promoter and $\operatorname{trpC}$ terminator sequences, present on the pGBFIN-49 vector, to drive expression in $A$. niger. The complete expression vector was transfected into $A$. niger, strain GBA307 [63], according to the method described by Punt and van den Hondel [65], and stable phleomycin-resistant transformants were obtained. After 5-10 days, isolated colonies were selected and transferred onto Potato Dextrose Agar (PDA, Difco) supplemented with $150-\mu \mathrm{g} / \mathrm{mL}$ phleomycin. After 5-7 days, spores were harvested by adding sterile water on top of the agar, resuspended and subsequently mixed $1: 1$ with $50 \%$ glycerol for storage at $-80^{\circ} \mathrm{C}$.

For enzyme production, the frozen spore suspension was plated on PDA and incubated at $30^{\circ} \mathrm{C}$. After 7 days, spores were collected by adding sterile water onto the agar, resuspended and washed with sterile water. This spore suspension was used to inoculate a $20-\mathrm{mL}$ preculture with corn steep liquor (CSL) medium in a 100$\mathrm{mL}$ baffled flask. CSL medium consisted of (in amount per liter): 100-g Corn Steep Solids (Roquette), 1-g $\mathrm{NaH}_{2} \mathrm{PO}_{4} \cdot \mathrm{H}_{2} \mathrm{O}, 0.5-\mathrm{g} \mathrm{MgSO}_{4} \cdot 7 \mathrm{H}_{2} \mathrm{O}, 10$-g glucose and 0.25-g Basildon (antifoam). The ingredients were dissolved in demineralized water, the $\mathrm{pH}$ was adjusted to pH 5.8 with $\mathrm{NaOH}$ or $\mathrm{H}_{2} \mathrm{SO}_{4}$, and the resulting growth medium was sterilized for $20 \mathrm{~min}$ at $120{ }^{\circ} \mathrm{C}$. After overnight cultivation in CSL medium at $34{ }^{\circ} \mathrm{C}$ and $170 \mathrm{rpm}$, the 20 -mL pre-culture was mixed with 80 -mL Fermentation Medium (FM). FM consisted of (in amount per liter): 150-g maltose, 60-g Soytone (peptone), 15- $\mathrm{g}\left(\mathrm{NH}_{4}\right)_{2} \mathrm{SO}_{4}$, 1-g $\mathrm{NaH}_{2} \mathrm{PO}_{4} \cdot \mathrm{H}_{2} \mathrm{O}, 15$-g $\mathrm{MgSO}_{4} \cdot 7 \mathrm{H}_{2} \mathrm{O}, 0.08$-g Tween 80, 0.02-g Basildon (antifoam), 20-g 2-( $N$-morpholino) ethanesulfonic acid (MES) and 1-g L-arginine. The ingredients were dissolved in demineralized water, the $\mathrm{pH}$ was adjusted to $\mathrm{pH} 6.2$ with $\mathrm{NaOH}$ or $\mathrm{H}_{2} \mathrm{SO}_{4}$, and the resulting fermentation medium was sterilized for $20 \mathrm{~min}$ at $120{ }^{\circ} \mathrm{C}$. Growth in FM was performed aerobically in 500$\mathrm{mL}$ baffled flasks with $100-\mathrm{mL}$ final volume at $36^{\circ} \mathrm{C}$ and $170 \mathrm{rpm}$. After 4 days, the broth was collected and centrifuged at 5,000 $\mathrm{g}$ for $10 \mathrm{~min}$ to remove cells and debris. The protein content of the supernatant was analyzed by SDS-PAGE (Additional file 1, Fig. S2).

Prior to purification, the supernatant was sterilized by filtration through, first, a $0.45-\mu \mathrm{m}$ filter and then a 0.22 $\mu \mathrm{m}$ filter, followed by concentration using a Vivaspin 10,000 Da spin column (GE Healthcare). The protein solution was loaded onto a HiPrep 26/10 Desalting Column (Sigma Aldrich) paired with an ÄKTA Prime Chromatography system $(7.0-\mathrm{mL} / \mathrm{min}$ flow, $50-\mathrm{mM}$ BisTris $\mathrm{HCl}$ buffer $\mathrm{pH}$ 7.0, 5- $\mathrm{mL}$ fractions collected). The elution profile was followed by monitoring the absorbance at 280 and $220 \mathrm{~nm}$. LPMO-containing fractions (based on $\mathrm{A}_{280}$ and SDS-PAGE analysis of the collected fractions) were pooled and concentrated by extensive centrifugation in Amicon Ultra centrifugal filters (Millipore) with a molecular mass cut-off of $10,000 \mathrm{Da}$. Next, the protein was purified further with anion exchange chromatography. A 5-mL HiTrap CaptoQ XL column was equilibrated with 
50-mM BisTris $\mathrm{HCl}$ buffer ( $\mathrm{pH}$ 7.0) before loading the protein sample. Elution was performed by applying a linear gradient from 0- to $1-\mathrm{M} \mathrm{NaCl}$ in $50-\mathrm{mM}$ BisTris $\mathrm{HCl}$ buffer ( $\mathrm{pH} 7.0)$ at a flow rate of $2 \mathrm{~mL} / \mathrm{min}$ in 10 column volumes. The elution profile was followed by monitoring the absorbance at 280 and $220 \mathrm{~nm}$. LPMO-containing fractions (based on $A_{280}$ and SDS-PAGE analysis of the collected fractions) were pooled and concentrated using Amicon Ultra centrifugal filters with a molecular mass cut-off of 10,000 Da (Millipore). The purity of the resulting TausLPMO9B preparation was confirmed by SDS-PAGE (Additional file 1: Fig. S2). After purification, TausLPMO9B was loaded with copper by incubating with 3-molar-fold excess of $\mathrm{CuSO}_{4}$ for $30 \mathrm{~min}$ in a thermomixer (Eppendorf ThermoMixer ${ }^{\mathrm{TM}} \mathrm{C}$, Hamburg, Germany) at room temperature as described before [66]. Excess copper was removed using a PD10 desalting column containing Sephadex G-25 resin (GE Healthcare Lifesciences), pre-equilibrated with $50-\mathrm{mM}$ sodium acetate buffer $\mathrm{pH}$ 5.0. The protein content was then measured using the ThermoScientific Pierce ${ }^{\mathrm{TM}}$ BCA assay according to the recommendations of the supplier.

\section{Structure-based sequence alignment and structural modeling}

A comparison between the TausLPMO9B sequence and sequences of other biochemically characterized AA9 was performed using the Clustal Omega multiple sequence alignment program (http://www.ebi.ac.uk/Tools/msa/ clust alo/). The structure-based sequence alignment was generated using ESPript [67]. The three-dimensional structure of TausLPMO9B was predicted with the Protein Homology/analogY Recognition Engine V 2.0 [68], and a model was built based on the available structure of the catalytic domain of NcLPMO9C from N. crassa [69] (PDB, 4D7U), which shares $44.1 \%$ amino acid identity with TausLPMO9B, and visualized with PyMOL version 2.3 (The PyMOL Molecular Graphics System, Version 1.2r3pre, Schrödinger, LLC.). Possible N-and O-glycosylation sites were predicted using NetNGlyc 1.0 (http:// www.cbs.dtu.dk/services/NetNGlyc/) and NetOGlyc 4.0 (http://www.cbs.dtu.dk/services/NetOGlyc-4.0/), respectively $[70,71]$. Possible disulfide bridges were predicted using DiANNA 1.1 [72] (http://clavius.bc.edu/ clotelab/ DiANNA/).

\section{Screening of substrates and reductants}

Unless specified otherwise, reducing agents were purchased from Sigma Aldrich (Steinheim, Germany). Avicel PH-101 was purchased from Merck Millipore (Burlington, MA, USA). $\beta$-glucan from oat spelt, glucomannan from konjac, wheat arabinoxylan, xyloglucan from tamarind seeds and cello-oligosaccharides (with a degree of polymerization, DP, of 3-6) were purchased from Megazyme (Bray, Ireland). Xylan from oat spelt was purchased from Serva (Brussels, Belgium). Cellobionic acid sodium salt was purchased from Synthose (Toronto, Canada). Phosphoric acid swollen cellulose (PASC) was prepared from Avicel PH-101 as previously described [73]. In short, 4-mg Avicel PH-101 was suspended in 100-mL ortho-phosphoric acid $(85 \% \mathrm{w} / \mathrm{v})$ with constant stirring. Once the cellulose was dissolved, $1900-\mathrm{mL}$ ice cold water was added. The mixture was left to sediment for $1 \mathrm{~h}$ at $4{ }^{\circ} \mathrm{C}$. This washing step was repeated three times. Subsequently, the pellet was washed with $1 \%$ sodium bicarbonate $(\mathrm{pH}$ 7.0) three times, until a neutral $\mathrm{pH}$ was reached. The pellet was washed again with water three times, followed by centrifugation at $4000 \mathrm{~g}$ for $10 \mathrm{~min}$. After removal of the supernatant, the pellet was homogenized with a Thorax Blender. The final dry matter content of the PASC was measured with a moisture analyzer (HB43-S Mettler-Toledo, Greifensee, Switzerland).

To test substrate preference, reaction mixtures $(250 \mu \mathrm{L})$ containing substrate $(0.1 \% \mathrm{w} / \mathrm{v}), 1-\mu \mathrm{M}$ LPMO and $1-\mathrm{mM}$ ascorbic acid were incubated in $50-\mathrm{mM}$ sodium acetate buffer pH 5.0 for $24 \mathrm{~h}$ at $45^{\circ} \mathrm{C}$, in a thermomixer (Eppendorf ThermoMixer ${ }^{\mathrm{TM}} \mathrm{C}$, Hamburg, Germany) with constant shaking at $600 \mathrm{rpm}$. To stop the reactions, samples were filtered through a 10,000 Da molecular weight cutoff PES filter fitted into an Eppendorf tube at 14,000 rpm for $10 \mathrm{~min}$. As positive controls, reaction mixtures containing $1-\mu \mathrm{M} \quad \mathrm{NcLPMO} 9 \mathrm{C}, 1-\mathrm{mg} / \mathrm{mL}$ substrate and 1 -mM ascorbic acid were prepared.

To test the effect of different electron donors, the same conditions as above were applied using PASC as substrate and either 1-mM L-DOPA, 1-mM cysteine, 1-mM gallic acid, $1-\mathrm{mg} / \mathrm{mL}$ kraft lignin (Sigma) or $1 \%(\mathrm{v} / \mathrm{v})$ water-soluble lignin derived from acid pretreated corn stover. The water-soluble lignin fraction was produced by separating the solid fraction of the pretreated biomass by centrifugation at 4,000 $g$ for $15 \mathrm{~min}$. Control reactions did not contain any reductant. All reactions were performed in triplicate.

\section{Enzyme activity}

To identify the optimal reaction conditions for TausLPMO9B, different $\mathrm{pH}$ values and temperatures were tested. Reaction mixtures (300- $\mu \mathrm{L}$ final volume) containing PASC $(0.1 \% \mathrm{w} / \mathrm{v}), 1-\mu \mathrm{M}$ LPMO and $1-\mathrm{mM}$ ascorbic acid were incubated in $50-\mathrm{mM}$ buffer at different $\mathrm{pH}$ values (sodium citrate-phosphate for $\mathrm{pH}$ 3.0, sodium acetate for $\mathrm{pH} 4.0$ and 5.0, BisTris/ $\mathrm{HCl}$ for $\mathrm{pH} 6.0$ and 7.0, Tris/HCl for $\mathrm{pH} 8.0$ and 9.0).

To study the activity of TausLPMO9B at different temperatures, the substrate and buffer were pre-incubated at different temperatures (ranging from 35 to $85{ }^{\circ} \mathrm{C}$ ), 
before adding the enzyme and reductant to generate reaction mixtures as described above. To follow reactions for longer periods (up to $72 \mathrm{~h}$ ), the reaction volume was doubled to $600 \mu \mathrm{L}$. For sampling, $100 \mu \mathrm{L}$ was withdrawn and filtered after $10 \mathrm{~min}, 30 \mathrm{~min}$ and $24 \mathrm{~h}$ at $4{ }^{\circ} \mathrm{C}$ and the solubilized oxidized cello-oligosaccharides in the supernatant were analyzed with high-performance anion exchange chromatography with pulsed amperometric detection (HPAEC-PAD) (see below). All reactions were performed in triplicate.

\section{The effect of $\mathrm{H}_{2} \mathrm{O}_{2}$ on the activity of TausLPMO9B}

To test the potential of $\mathrm{H}_{2} \mathrm{O}_{2}$ as a co-substrate for TausLPMO9B, reaction mixtures $(500-\mu \mathrm{L}$ total volume) containing $0.1 \%(\mathrm{w} / \mathrm{v})$ PASC, $1-\mathrm{mM}$ or $100-\mu \mathrm{M}$ ascorbic acid, 1- $\mu \mathrm{M}$ enzyme and various concentrations of $\mathrm{H}_{2} \mathrm{O}_{2}$ were incubated in $50-\mathrm{mM}$ sodium acetate buffer $\mathrm{pH} 5.0$ under standard, i.e., aerobic, conditions. At each time point, $100-\mu \mathrm{L}$ samples were withdrawn, filtered and analyzed with HPAEC-PAD to quantify the release of oxidized products.

\section{Analysis of oxidized LPMO products with HPAEC-PAD}

Filtrates of the reactions were analyzed by HPAECPAD on a Dionex ICS-5000 system (Sunnyvale, CA, USA) equipped with a CarboPac PA1 guard column $(2 \times 50 \mathrm{~mm})$ and a CarboPac PA1 analytical column $(2 \times 250 \mathrm{~mm})$. The flow was set at $0.25 \mathrm{~mL} / \mathrm{min}$, with an injection volume of $10 \mu \mathrm{L}$. For elution, two mobile phases were used: $0.1-\mathrm{M} \mathrm{NaOH}$ as eluent $\mathrm{A}, 1-\mathrm{M} \mathrm{NaOAc}$ in $0.1-\mathrm{M} \mathrm{NaOH}$ as eluent $\mathrm{B}$. The following gradient was applied: linear increase from 0 to $10 \% \mathrm{~B}$ in $10 \mathrm{~min}$, then to $30 \% \mathrm{~B}$ in the next $15 \mathrm{~min}$, followed by an exponential gradient to $100 \% \mathrm{~B}$ in $5 \mathrm{~min}$. The column was reconditioned before every injection by running $0 \% \mathrm{~B}$ for $9 \mathrm{~min}$. Assignments of $\mathrm{C} 1$ - and C4-oxidized peaks was based on comparison with products released from reference enzymes performing either C1- or C4-oxidation (NcLPMO9F and NcLPMO9C, respectively), which were produced as described elsewhere [45]. Gluconic acid and cellobionic acid were assigned and quantified using available standards (purchased from Megazyme and Synthose, respectively). To analyze the chromatograms, Chromeleon version 7.0 software (Thermo Fisher Scientific, Waltham, MA, USA) was used.

\section{Saccharification in bioreactors}

Acid pretreated corn stover was obtained from SEKAB E-Technology, Örnsköldsvik, Sweden. The pretreatment was conducted in a pilot scale reactor, operated at steady-state conditions of $182{ }^{\circ} \mathrm{C}, 4.7$ min residence time and an effective $\mathrm{H}_{2} \mathrm{SO}_{4}$ acid concentration of
$0.35 \%(\mathrm{w} / \mathrm{w})$ in the liquid, aiming at a $\mathrm{pH}$ of 2.5 [74]. The composition of this material is reported in Tables S4-S7 in Additional file 1. Saccharification was conducted in 1.5-L bioreactors (Infors HT Minifors) at $50{ }^{\circ} \mathrm{C}$ for $140 \mathrm{~h}$, at $\mathrm{pH} 5.0$ (controlled through automatic addition of $4 \mathrm{~N} \mathrm{NaOH}$ ) and using a mixing speed of $150 \mathrm{rpm}$. Industrial conditions were downscaled to a working volume of $1 \mathrm{~L}$ with $10 \%(\mathrm{w} / \mathrm{w})$ dry matter, and saccharification was started by addition of a mixture of Celluclast ${ }^{\circledR}$ (SigmaAldrich) (at $2.5 \mathrm{mg} /$ gberk dry matter) and an in-house produced $A$. niger $\beta$-glucosidase (at $300 \mathrm{U} / \mathrm{g}$ dry matter), with or without LPMO (at $0.1 \mathrm{mg} / \mathrm{g}$ dry matter). Feedstock slurries were premixed under constant $\mathrm{N}_{2}$ for $16 \mathrm{~h}$ to ensure similar conditions in all reactors prior to enzyme loading. Reactions were carried out either aerobically or anaerobically through constant sparging of the headspace with air (labeled in figures as $\mathrm{O}_{2}$ ) or $\mathrm{N}_{2}$. To avoid microbial contamination, $0.2-\mu \mathrm{m}$ filter disks were installed at the gas inlets and outlets. To confirm anaerobic conditions, an external oxygen sensor (Mettler-Toledo, Greifensee, Switzerland) was used to check the absence of dissolved oxygen in the liquid phase during saccharification. For the reactions with $\mathrm{H}_{2} \mathrm{O}_{2}$, hydrolysis was performed under $\mathrm{N}_{2}$, and $\mathrm{H}_{2} \mathrm{O}_{2}$ was added 3 times per day to a final concentration of 100-200 $\mu \mathrm{M}$ per addition. Samples were collected at different time points and immediately inactivated by addition of $4 \mathrm{~N} \mathrm{NaOH}$. Glucose released during saccharification was analyzed by high-performance liquid chromatography (HPLC) on a Dionex Ultimate 3000 (Dionex, Sunnyvale, USA). Products were separated using an Aminex ${ }^{\circledR}$ HPX-87P $300 \times 7.8-\mathrm{mm}$ column, with ultrapure water as eluent at a flow of $0.6 \mathrm{~mL} /$ min and a temperature of $85{ }^{\circ} \mathrm{C}$. Hydrolysis reactions were performed in duplicate.

\section{Thermal stability}

The thermal stability of TausLPMO9B was assessed using a thermal shift assay kit (Thermofisher, Massachusetts, USA) at $\mathrm{pH}$ ranging from 3.0 to 8.0 in different buffers (sodium citrate-phosphate for $\mathrm{pH}$ 3.0, sodium acetate for $\mathrm{pH} 5.0$, BisTris/ $\mathrm{HCl}$ for $\mathrm{pH} 7.0$ and Tris $/ \mathrm{HCl}$ for $\mathrm{pH}$ 8.0). Reactions containing 10- $\mu \mathrm{M}$ LPMO in each buffer and reference dye were prepared in a 96 well plate (Bio-rad). The plate was sealed with an optical adhesive film before incubation in a C1000 Dx Thermal Cycler with CFX96 Deep Well Dx Optical Reaction Module (Bio-Rad). The plate was heated from 25 to $95{ }^{\circ} \mathrm{C}$ with stepwise increments of $0.5^{\circ} \mathrm{C}$ per min each followed by a 30-s hold, while fluorescence, with an excitation/emission wavelength at $488 / 602 \mathrm{~nm}$, was monitored. All reactions were carried out in triplicate. 


\section{Peptide map LC-MS/MS}

$50 \mu \mathrm{l}$ sample was added to $450-\mu \mathrm{l} 100-\mathrm{mM}$ ammonium bicarbonate (Sigma Aldrich) and 5- $\mu \mathrm{l} 500-\mathrm{mM}$ dithiothreitol (DTT, Sigma Aldrich) in 100-mM ammonium bicarbonate. The cysteines were reduced by 30-min incubation at $55{ }^{\circ} \mathrm{C}$. $5-\mu \mathrm{l} 550-\mathrm{mM}$ freshly prepared iodoacetamide (IAA, Sigma Aldrich) in 100-mM ammonium bicarbonate was added, cysteines were alkylated by 30 -min incubation at $20^{\circ} \mathrm{C}$. The reaction was quenched by addition of $1-\mu \mathrm{l} 500-\mathrm{mM}$ DTT in 100-mM ammonium bicarbonate. $20-\mu \mathrm{l} 0.25-\mu \mathrm{g} / \mu \mathrm{l}$ trypsin gold (Promega, Madison WI, USA) in 5-mM $\mathrm{HCl}$ was added, and the sample was digested by $4-\mathrm{h}$ incubation at $37{ }^{\circ} \mathrm{C}$. Another $4-\mu \mathrm{l} 0.25-\mu \mathrm{g} / \mu \mathrm{l}$ trypsin gold was added followed by $1-\mathrm{h}$ incubation at $37^{\circ} \mathrm{C}$ to ensure completion of the digestion. The sample was split into three $100-\mu$ f fractions: (1) one part was acidified with $1-\mu l$ formic acid and analyzed directly; (2) one part was digested with $1-\mu \mathrm{l} 1-\mathrm{U} / \mu \mathrm{l}$ PNGase F (Promega, Madison WI, USA) for $1 \mathrm{~h}$ at $37^{\circ} \mathrm{C}$, then acidified with $1-\mu \mathrm{l}$ formic acid and analyzed; and (3) one part was acidified with $10-\mu l 5 \%$ formic acid to $\mathrm{pH} \sim 5$, then digested with $10-\mu \mathrm{l} 5-\mathrm{U} / \mathrm{mL}$ Endo Hf (Roche Applied Science, Penzberg, Germany) for $1 \mathrm{~h}$ at $37{ }^{\circ} \mathrm{C}$, then acidified further with $1-\mu \mathrm{l}$ formic acid and analyzed.

Samples were analyzed by liquid chromatographytandem mass spectrometry (LC-MS/MS). The system consisted of a Vanquish UHPLC coupled to a Q Exactive Plus Orbitrap MS (Thermo Scientific, San Jose, CA, USA)

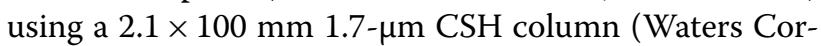
poration, Milford, MA, USA); the column oven was set to $50{ }^{\circ} \mathrm{C}$, the injection volume was $10 \mu \mathrm{l}$, and the flow rate was set to $0.4 \mathrm{~mL} / \mathrm{min}$. Peptides were separated using reverse-phase chromatography using a gradient of water with $0.1 \%$ formic acid (solvent A) and $90 \%$ acetonitrile with $0.1 \%$ formic acid (solvent B) from $6.3 \%$ B to $55 \%$ B in $10 \mathrm{~min}$, total runtime of $15 \mathrm{~min}$. Data-dependent acquisition (DDA) was performed with a resolution setting at 35,000 within the $\mathrm{m} / z$ range $400-1,600$ and a maximum injection time of $75 \mathrm{~ms}$, followed by high-energy collision-induced dissociation-activated (HCD) MS/MS on the top 5 most abundant precursors using a resolution setting of 17,500 and a $\mathrm{m} / z$ range $50-2,000$ with a maximum injection time of $50 \mathrm{~ms}$. The minimum intensity threshold for MS/MS was 1,000 counts, and peptide species with 1 and $>8$ charges were excluded. MS/ MS spectra were analyzed with the MS Amanda search engine in Proteome Discoverer, version 2.3, against the $A$. niger database (in-house) and the complete and mature TausLPMO9B sequence, lacking the signal peptide. Protein N-terminal methylation, deamidation (N/Q), oxidation $(\mathrm{M})$ were set as variable modification, and carbamidomethylation (C) was set as fixed modification. Precursor mass accuracy was set to $10 \mathrm{ppm}$ and fragment mass accuracy to $0.02 \mathrm{Da}$. Trypsin was used as cleavage preference allowing up to 3 missed cleavages. Fixed Value PSM Validator was used, and only high confident peptide matches were considered for the peptide map.

\section{Intact protein LC-MS}

The sample was diluted to $50 \mu \mathrm{g} / \mathrm{mL}$ in water containing $2 \%(\mathrm{w} / \mathrm{v})$ formic acid, prior to LC-MS analysis. LC-MS was performed using an ACQUITY I-class UPLC coupled to a Synapt G2S quadrupole-time-of-flight (Q-TOF) mass spectrometer (Waters Corporation, USA). $5 \mu$ was injected into a $\mathrm{C} 4$ analytical column (Acquity UPLC Protein BEH300 $1.7 \mu \mathrm{m} 300 \AA$ pore size $2.1 \times 50 \mathrm{~mm}$, Waters Corporation, USA). The column temperature was set to $75{ }^{\circ} \mathrm{C}$. As mobile phase, a gradient of premixed $0.1 \%$ formic acid in water (A), and premixed $0.1 \%$ formic acid in acetonitrile (B) was used at $400 \mu \mathrm{l} / \mathrm{min}$. The first $2 \mathrm{~min}$ was kept isocratic at $97 \% \mathrm{~A}$, followed by a decrease in the percentage of mobile phase A to $83 \%$ in $0.2 \mathrm{~min}$. From 2.2 to $8.0 \mathrm{~min}$, the percentage A was further decreased to $56 \%$, after which the column was kept at $56 \%$ A for $2 \mathrm{~min}$, followed by an increase to $97 \%$ A in $10 \mathrm{~min}$. Mass calibration was performed over a mass range $(\mathrm{m} / \mathrm{z})$ of $500-3500$ using sodium-trifluoroacetate clusters. Mass correction on the flight was performed using leucine enkephalin (Sigma) as lockmass. The mass spectra were recorded in continuum resolution mode. MS settings used are hereby listed: Capillary $1 \mathrm{kV}$, Sampling Cone 40, Source Offset 80, Source Temperature $120{ }^{\circ} \mathrm{C}$, Desolvation Temperature $400{ }^{\circ} \mathrm{C}$, Cone Gas $50 \mathrm{~L} / \mathrm{h}$, Desolvation Gas $700 \mathrm{~L} / \mathrm{h}$, and Nebuliser Gas 6 Bar. The molecular mass of the protein was calculated by maximum entropy deconvolution using MaxEnt2, using the following parameters: Ranges 20,000:45,000, Resolution 0.9 Da/channel (could be varied), Damage model Uniform Gaussian $0.75 \mathrm{Da}$, and iteration to convergence.

\section{Supplementary information}

Supplementary information accompanies this paper at https://doi. org/10.1186/s13068-020-01836-3.

Additional file 1. Tables and figures.

\section{Abbreviations}

AA: Auxiliary activity; CAZymes: Carbohydrate Active enZymes; CSL: Corn steep liquor; DM: Dry matter; DP: Degree of polymerization; GH: Glycoside hydrolase; HPLC: High-performance liquid chromatography; HPAEC-PAD: High-performance anion exchange chromatography with pulsed amperometric detection; LPMO: Lytic polysaccharide monooxygenase; PASC: Phosphoric acid swollen cellulose; PCS: Pretreated corn stover; PTM: Post-translational modification.

\section{Acknowledgements}

This work was performed within OXYTRAIN, a project under the EU's Horizon 2020 program; Grant Number 722390. The authors thank Olaf Schouten for his support in protein mass analysis using spectrometry. 


\section{Authors' contributions}

FC carried out the research work and drafted the manuscript draft. LB, MvdB, $A V$ and $V E$ have assisted in the design of the experiments, provided feedback on results, and carried out supervision and refining of the manuscript. MA supervised the MS analysis and interpretation. All authors read and approved the final manuscript.

\section{Funding}

The research for this work has received funding from the European Union's Horizon 2020 research and innovation program under the Marie SkłodowskaCurie grant agreement no. 722390 .

\section{Availability of data and materials}

The dataset(s) supporting the conclusions of this article is(are) included within the article (and its additional file(s)).

\section{Ethics approval and consent to participate}

Not applicable.

\section{Consent for publication}

Not applicable.

\section{Competing interests}

The authors declare that they have no competing interests.

\section{Author details}

${ }^{1}$ DSM Biotechnology Center, PP 699-0310, Alexander Fleminglaan 1, 2613 AX Delft, The Netherlands. ${ }^{2}$ Molecular Enzymology, Groningen Biomolecular Sciences and Biotechnology Institute, University of Groningen, Groningen, The Netherlands. ${ }^{3}$ Faculty of Chemistry, Biotechnology and Food Science, Norwegian University of Life Sciences (NMBU), Ås, Norway.

Received: 11 June 2020 Accepted: 19 November 2020

Published online: 30 November 2020

\section{References}

1. Cherubini F. The biorefinery concept: using biomass instead of oil for producing energy and chemicals. Energy Convers Manag. 2010;51(7):1412-21.

2. Sims REH, Mabee W, Saddler JN, Taylor M. An overview of second generation biofuel technologies. Bioresour Technol. 2010;101(6):1570-80.

3. Himmel ME, Ding S, Johnson DK, Adney WS. Biomass recalcitrance: engineering plants and enzymes for biofuels production. Science. 2007;315(5813):804-7.

4. Jørgensen $\mathrm{H}$, Kristensen JB, Felby C. Enzymatic conversion of lignocellulose into fermentable sugars: challenges and opportunities. Biofuels Bioprod Bioref. 2007:1:119-34.

5. Pauly M, Keegstra K. Cell-wall carbohydrates and their modification as a resource for biofuels. Plant J. 2008;54(4):559-68.

6. Galbe M, Zacchi G. Pretreatment of lignocellulosic materials for efficient bioethanol production Olssen L, editor. Adv Biochem Eng Biotechnol. 2007;108:1-40.

7. Foust TD, Aden A, Dutta A, Phillips S. An economic and environmental comparison of a biochemical and a thermochemical lignocellulosic ethanol conversion processes. Cellulose. 2009;16(4):547-65.

8. Lombard V, Golaconda Ramulu H, Drula E, Coutinho PM, Henrissat B. The carbohydrate-active enzymes database (CAZy) in 2013. Nucleic Acids Res. 2014:42(Database issue):D490-5.

9. Vaaje-Kolstad G, Westereng B, Horn SJ, Sorlie M, et al. An oxidative enzyme boosting the enzymatic conversion of recalcitrant polysaccharides. Science. 2010;330(6001):219-22.

10. Harris PV, Welner D, MCFarland KC, Re E, Poulsen JN, Brown K, et al. Stimulation of lignocellulosic biomass hydrolysis by proteins of glycoside hydrolase family 61: structure and function of a large, enigmatic family. Biochemistry. 2010;49:3305-16.

11. Hu J, Chandra R, Arantes V, Gourlay K, van Dyk JS, Saddler JN. The addition of accessory enzymes enhances the hydrolytic performance of cellulase enzymes at high solid loadings. Bioresour Technol. 2015;186:149-53.

12. Merino S, Cherry J. Progress and challenges in enzyme development for biomass utilization. Adv Biochem Eng Biotechnol. 2007;108:95-120.
13. Johansen KS. Discovery and industrial applications of lytic polysaccharide mono-oxygenases. Biochem Soc Trans. 2016;44(1):143-9.

14. Chylenski P, Bissaro B, Sørlie M, Røhr ÅK, Va A, Horn SJ, et al. Lytic polysaccharide monooxygenases in enzymatic processing of lignocellulosic biomass. ACS Catal. 2019:9:4970-91.

15. Levasseur A, Drula E, Lombard V, Coutinho PM, Henrissat B. Expansion of the enzymatic repertoire of the CAZy database to integrate auxiliary redox enzymes. Biotechnol Biofuels. 2013;6:41.

16. Kracher D, Scheiblbrandner S, Felice AKG, Breslmayr E, Preims M, Ludwicka K, et al. Extracellular electron transfer systems fuel cellulose oxidative degradation. Science. 2016;352(6289):1098-102

17. Walton PH, Davies GJ. On the catalytic mechanisms of lytic polysaccharide monooxygenases. Curr Opin Chem Biol. 2016;31:195-207.

18. Bissaro B, Røhr ÅK, Müller G, Chylenski P, Skaugen M, Forsberg Z, et al. Oxidative cleavage of polysaccharides by monocopper enzymes depends on $\mathrm{H}_{2} \mathrm{O}_{2}$. Nat Chem Biol. 2017;13(10):1123-8.

19. Frommhagen M, Koetsier MJ, Westphal AH, Visser J, Hinz SWA, Vincken JP, et al. Lytic polysaccharide monooxygenases from Myceliophthora thermophila $\mathrm{C} 1$ differ in substrate preference and reducing agent specificity. Biotechnol Biofuels. 2016:9(1):1-17.

20. Westereng B, Cannella D, Wittrup Agger J, Jørgensen H, Larsen Andersen M, Eijsink VGH, et al. Enzymatic cellulose oxidation is linked to lignin by longrange electron transfer. Sci Rep. 2015;5:18561.

21. Müller G, Várnai A, Johansen KS, Eijsink VGH, Horn SJ. Harnessing the potential of LPMO-containing cellulase cocktails poses new demands on processing conditions. Biotechnol Biofuels. 2015;8:187.

22. Muraleedharan MN, Zouraris D, Karantonis A, Topakas E, Sandgren M, Rova $U$, et al. Effect of lignin fractions isolated from different biomass sources on cellulose oxidation by fungal lytic polysaccharide monooxygenases. Biotechnol Biofuels. 2018;11(1):1-15. https://doi.org/10.1186/s1306 8-018-1294-6.

23. Kont R, Pihlajaniemi V, Borisova AS, Aro N, Marjamaa K, Loogen J, et al. The liquid fraction from hydrothermal pretreatment of wheat straw provides lytic polysaccharide monooxygenases with both electrons and $\mathrm{H}_{2} \mathrm{O}_{2}$ COsubstrate. Biotechnol Biofuels. 2019;12:235.

24. Rodríguez-Zúñiga UF, Cannella D, Giordano RDC, Giordano RDLC, Jørgensen $\mathrm{H}$, Felby $\mathrm{C}$. Lignocellulose pretreatment technologies affect the level of enzymatic cellulose oxidation by LPMO. Green Chem. 2015;17(5):2896-903.

25. Phillips CM, Beeson WT, Cate JH, Marletta MA. Cellobiose dehydrogenase and a copper-dependent polysaccharide monooxygenase potentiate cellulose degradation by Neurospora crassa. ACS Chem Biol. 2011;6(12):1399-406.

26. Horn SJ, Vaaje-Kolstad G, Westereng B, Eijsink VGH. Novel enzymes for the degradation of cellulose. Biotechnol Biofuels. 2012;5:45.

27. Frandsen KEH, Simmons TJ, Dupree P, Poulsen JCN, Hemsworth GR, Ciano L, et al. The molecular basis of polysaccharide cleavage by lytic polysaccharide monooxygenases. Nat Chem Biol. 2016;12(4):298-303.

28. Kuusk S, Bissaro B, Kuusk P, Forsberg Z, Eijsink VGH, Sørlie M, et al. Kinetics of $\mathrm{H}_{2} \mathrm{O}_{2}$-driven degradation of chitin by a bacterial lytic polysaccharide monooxygenase. J Biol Chem. 2018:293(2):523-31.

29. Kuusk S, Kont R, Kuusk P, Heering A, Sørlie M, Bissaro B, et al. Kinetic insights into the role of the reductant in $\mathrm{H}_{2} \mathrm{O}_{2}$-driven degradation of chitin by a bacterial lytic polysaccharide monooxygenase. J Biol Chem. 2018;294:1516-28.

30. Bissaro B, Streit B, Isaksen I, Eijsink VGH, Beckham GT, DuBois JL, et al. Molecular mechanism of the chitinolytic peroxygenase reaction. Proc Natl Acad Sci USA. 2020;117(3):1504-13.

31. Jones SM, Transue WJ, Meier KK, Kelemen B, Solomon El. Kinetic analysis of amino acid radicals formed in $\mathrm{H}_{2} \mathrm{O}_{2}$-driven $\mathrm{CU}^{\prime} \mathrm{LPMO}$ reoxidation implicates dominant homolytic reactivity. Proc Natl Acad Sci USA 2020;117(22):11916-22.

32. Riley R, Salamov AA, Brown DW, Nagy LG, Floudas D, Held BW, et al. Extensive sampling of basidiomycete genomes demonstrates inadequacy of the white-rot/brown-rot paradigm for wood decay fungi. Proc Natl Acad Sci USA. 2014;111(27):9923-8.

33. Petrović DM, Várnai A, Dimarogona M, Mathiesen $G$, Sandgren $M$, Westereng $B$, et al. Comparison of three C4-oxidizing lytic polysaccharide monooxygenases from Neurospora crassa suggests different roles in plant cell wall degradation. J Biol Chem. 2019;294:15068-81.

34. Tsang A, Butler G, Powlowski J. Novel cell wall deconstruction enzymes of Thielavia australiensis and uses thereof. 2014; Patent Number WO 2014/140171 A1. 
35. Punt, Peter J, Burlingame RP, Pynnonen CM, Olson, Phillip T, Wery J, Visser JH, et al. Chrysosporium lucknowense protein production system. 2010; Patent Number WO/2010/107303.

36. Aehle W, Bott RR, Nikolaev I, Scheffers M, Van Solingen P, Vroemen C. Glucoamylase variants with altered properties. 2009; Patent Number WO 2009/048488.

37. Quinlan RJ, Sweeney MD, Lo Leggio L, Otten H, Poulsen J-CN, Johansen $\mathrm{KS}$, et al. Insights into the oxidative degradation of cellulose by a copper metalloenzyme that exploits biomass components. Proc Natl Acad Sci USA. 2011;108(37):15079-84.

38. Petrović DM, Bissaro B, Chylenski P, Skaugen M, Sørlie M, Jensen MS, et al. Methylation of the N-terminal histidine protects a lytic polysaccharide monooxygenase from auto-oxidative inactivation. Protein Sci. 2018;27(9):1636-50

39. Li X, Beeson WT IV, Phillips CM, Marletta MA, Cate JHD. Structural basis for substrate targeting and catalysis by fungal polysaccharide monooxygenases. Structure. 2012;20(6):1051-61.

40. Fernandes S, Murray PG, Tuohy MG. Enzyme systems from the thermophilic fungus Talaromyces emersonii for sugar beet bioconversion. BioResources. 2008;3(3):898-909.

41. Thanh VN, Thuy NT, Huong HTT, Hien DD, Hang DTM, Anh DTK, et al. Surveying of acid-tolerant thermophilic lignocellulolytic fungi in Vietnam reveals surprisingly high genetic diversity. Sci Rep. 2019;9:3674.

42. Hüttner S, Várnai A, Petrovic DM, Bach CX, Kim DT, Vu Nguyen T, et al. Specific xylan activity revealed for AA9 Iytic polysaccharide monooxygenases of the thermophilic fungus Malbranchea cinnamomea. Appl Environ Microbiol. 2019:85(23):e01408-e1419.

43. Hansson H, Karkehabadi S, Mikkelsen N, Douglas NR, Kim S, Lam A, et al. High-resolution structure of a lytic polysaccharide monooxygenase from Hypocrea jecorina reveals a predicted linker as an integral part of the cataIytic domain. J Biol Chem. 2017;292(46):19099-109.

44. Laurent CVFP, Sun P, Scheiblbrandner S, Csarman F, Cannazza P, Frommhagen $\mathrm{M}$, et al. Influence of lytic polysaccharide monooxygenase active site segments on activity and affinity. Int J Mol Sci. 2019;20(24):6219.

45. Kittl R, Kracher D, Burgstaller D, Haltrich D, Ludwig R. Production of four Neurospora crassa lytic polysaccharide monooxygenases in Pichia pastoris monitored by a fluorimetric assay. Biotechnol Biofuels. 2012;5:79.

46. Forsberg Z, Bissaro B, Gullesen J, Dalhus B, Vaaje-Kolstad G, Eijsink VGH. Structural determinants of bacterial lytic polysaccharide monooxygenase functionality. J Biol Chem. 2018;293(4):1397-412.

47. Danneels B, Tanghe M, Desmet T. Structural features on the substrate-binding surface of fungal lytic polysaccharide monooxygenases determine their oxidative regioselectivity. Biotechnol J. 2019;14(3):e1800211.

48. Vu W, Beeson WT, Phillips CM, Cate JHD, Marletta MA. Determinants of regioselective hydroxylation in the fungal polysaccharide monooxygenases. J Am Chem Soc. 2014;136(2):562-5.

49. Lenfant N, Hainaut M, Terrapon N, Drula E, Lombard V, Henrissat B. A bioinformatics analysis of 3400 lytic polysaccharide oxidases from family AA9. Carbohydr Res. 2017:448:166-74.

50. Bennati-Granier C, Garajova S, Champion C, Grisel S, Haon M, Zhou S, et al. Substrate specificity and regioselectivity of fungal AA9 Iytic polysaccharide monooxygenases secreted by Podospora anserina. Biotechnol Biofuels. 2015:8(1):1-14.

51. Hegnar OA, Petrovic DM, Bissaro B, Alfredsen G, Várnai A, Eijsink VGH. $\mathrm{pH}$-dependent relationship between catalytic activity and hydrogen peroxide production shown via characterization of a lytic polysaccharide monooxygenase from Gloeophyllum trabeum. Appl Environ Microbiol. 2019:85(5):e02612-e2618.

52. Frommhagen M, Westphal AH, Hilgers R, Koetsier MJ, Hinz SWA, Visser J, et al. Quantification of the catalytic performance of C1-cellulose-specific lytic polysaccharide monooxygenases. Appl Microbiol Biotechnol. 2018;102(3):1281-95.

53. Hu J, Arantes V, Pribowo A, Gourlay K, Saddler JN. Substrate factors that influence the synergistic interaction of AA9 and cellulases during the enzymatic hydrolysis of biomass. Energy Environ Sci. 2014;7:2308-15.

54. Müller G, Chylenski P, Bissaro B, Eijsink VGH, Horn SJ. The impact of hydrogen peroxide supply on LPMO activity and overall saccharification efficiency of a commercial cellulase cocktail. Biotechnol Biofuels. 2018;11:209. https://doi. org/10.1186/s13068-018-1199-4

55. Weiss RF. Solubility of nitrogen, oxygen and argon in water and seawater. Deep-Sea Res. 1970;17:721-35.
56. Hess M. Thermoacidophilic proteins for biofuel production. Trends Microbiol. 2008;16(9):414-9.

57. Filandr F, Man P, Halada P, Chang H, Ludwig R, Kracher D. The $\mathrm{H}_{2} \mathrm{O}_{2}$-dependent activity of a fungal lytic polysaccharide monooxygenase investigated with a turbidimetric assay. Biotechnol Biofuels. 2020;13:37.

58. Bissaro B, Várnai A, Røhr ÅK, Eijsink VGH. Oxidoreductases and reactive oxygen species in conversion of lignocellulosic biomass. Microbiol Mol Biol Rev. 2018;82(4):1-51

59. Kracher D, Forsberg Z, Bissaro B, Gangl S, Preims M, Sygmund C, et al. Polysaccharide oxidation by lytic polysaccharide monooxygenase is enhanced by engineered cellobiose dehydrogenase. FEBS J. 2019;287(5):897-908.

60. Berka RM, Grigoriev IV, Otillar R, Salamov AA, Grimwood J, Reid I, et al. Comparative genomic analysis of the thermophilic biomass-degrading fungi Myceliophthora thermophila and Thielavia terrestris. Nat Biotechnol. 2011;29(10):922-7.

61. McClendon SD, Batth T, Petzold CJ, Adams PD, Simmons BA, Singer SW. Thermoascus aurantiacus is a promising source of enzymes for biomass deconstruction under thermophilic conditions. Biotechnol Biofuels. 2012;5:54.

62. Várnai A, Umezawa K, Yoshida M, Eijsink VGH. The pyrroloquinolinequinonedependent pyranose dehydrogenase from Coprinopsis cinerea drives lytic polysaccharide monooxygenase action. Appl Environ Microbiol. 2018;84(11):e00156-e218.

63. Tsang A, Powlowski J, Butler G. Novel cell wall deconstuction enzymes of Malbranchea cinnamomea, Thielavia australiensis, and Paecilomyces byssochlamydoides, and uses thereof. 2014; Patent Number WO/2014/138983.

64. Aslanidis C, de Jong PJ. Ligation-independent cloning of PCR products (LICPCR). Nucleic Acids Res. 1990;18:6069-74.

65. Punt PJ, van den Hondel CA. Transformation of filamentous fungi based on hygromycin B and phleomycin resistance marker. Methods Enzymol. 1992;215:447-57.

66. Forsberg Z, Mackenzie AK, Sørlie M, Røhr ÅK, Helland R, Arvai AS, et al. Structural and functional characterization of a conserved pair of bacterial cellulose-oxidizing lytic polysaccharide monooxygenases. Proc Natl Acad Sci USA. 2014;111(23):8446-51.

67. Robert $X$, Gouet P. Deciphering key features in protein structures with the new ENDscript server. Nucleic Acids Res. 2014;42:W320-4.

68. Kelley LA, Mezulis S, Yates CM, Wass MN, Sternberg MJE. The Phyre2 web portal for protein modeling, prediction and analysis. Nat Protoc. 2015;10(6):845-58.

69. Borisova AS, Isaksen T, Dimarogona M, Kognole AA, Mathiesen G, Várnai $A$, et al. Structural and functional characterization of a lytic polysaccharide monooxygenase with broad substrate specificity. J Biol Chem. 2015;290(38):22955-69.

70. Gupta R, Jung E, Brunak S. Prediction of N-glycosylation sites in human proteins. 2004;46:203-6.

71. Steentoft C, Vakhrushev SY, Joshi HJ, Kong Y, Vester-Christensen MB, Schjoldager KTBG, et al. Precision mapping of the human O-GalNAc glycoproteome through SimpleCell technology. EMBO J. 2013;32(10):1478-88.

72. Ferrè F, Clote P. Disulfide connectivity prediction using secondary structure information and diresidue frequencies. Bioinformatics. 2005;21 (10):2336-46.

73. Percival Zhang YH, Cui J, Lynd LR, Kuang LR. A transition from cellulose swelling to cellulose dissolution by o-phosphoric acid: evidence from enzymatic hydrolysis and supramolecular structure. Biomacromol. 2006;7(2):644-8.

74. Schell DJ, Farmer J, Newman M, McMillan JD. Dilute-sulfuric acid pretreatment of corn stover in pilot-scale reactor: investigation of yields, kinetics, and enzymatic digestibilities of solids. Appl Biochem Biotechnol. 2003;105-108:69-86.

75. Wu M, Beckham GT, Larsson AM, Ishida T, Kim S, Payne CM, et al. Crystal structure and computational characterization of the lytic polysaccharide monooxygenase GH61D from the basidiomycota fungus Phanerochaete chrysosporium. J Biol Chem. 2013;288(18):12828-39.

\section{Publisher's Note}

Springer Nature remains neutral with regard to jurisdictional claims in published maps and institutional affiliations. 